\title{
Producing Hollow Shafts in a New Horizontal Mill by Novel Flat-Knifing Cross-Wedge Rolling With Single Guide
}

\section{Longfei Lin}

University of Science and Technology Beijing https://orcid.org/0000-0001-5513-3829

\section{Baoyu Wang ( $\sim$ bywang@ustb.edu.cn )}

University of Science and Technology Beijing

Jinxia Shen

University of Science and Technology Beijing

Tao Liu

University of Science and Technology Beijing

\section{Research Article}

Keywords: Flat-knifing cross-wedge rolling, Horizontal cross-wedge rolling mill, Multifunctional rolling mill, Single guide rolling, Hollow shafts rolling

Posted Date: June 3rd, 2021

DOl: https://doi.org/10.21203/rs.3.rs-569126/v1

License: (9) This work is licensed under a Creative Commons Attribution 4.0 International License. Read Full License

Version of Record: A version of this preprint was published at The International Journal of Advanced Manufacturing Technology on October 3rd, 2021. See the published version at https://doi.org/10.1007/s00170-021-08023-0. 

knifing cross-wedge rolling with single guide

4 a School of Mechanical Engineering, University of Science and Technology Beijing,

$5 \quad$ Beijing 100083, China

$6 \quad \mathrm{~b}$ Beijing Laboratory of Metallic Materials and Processing for Modern Transportation,

7 Beijing 100083, China

$8 \quad *$ Corresponding author: Baoyu Wang

9 E-mail address: bywang@ustb.edu.cn

10 Tel: $+86-010-82375671$

11 Fax: +86-010-82375671

12 Postal address: No.30 Xueyuan Road, Haidian District, Beijing 100083, China 


\section{Abstract}

To meet the requirement of lightweight, there are increasing solid shafts being designed to be hollow in transportation industry. In this study, a novel method of flatknifing cross-wedge rolling (FCWR) with single guide is proposed including a modified roller, a horizontal mill and a single-guide structure, and its key problems are studied by numerical simulations and experimental tests. A mathematical model of FCWR roller is established, which reveals the wedge length of rollers is effectively reduced by modifying knifing wedge from normalized roller. Further, a horizontal multifunctional mill is invented and constructed to carry out the FCWR experiment with single guide. According to the results from the numerical simulations and corresponding experiments, it is observed that the typical defects of hole expansion and knifing groove are absolutely avoided because the improved flat-knifing wedge produces a radial force to shrink the inner hole and avoid the deformation concentration of the outer surface during knifing stage. Moreover, the single guide rolling performed in the horizontal mill efficiently improve rolling stability because the workpiece is restricted into a smaller workspace. To the authors' knowledge, all these integrated improvements of FCWR roller, single guide rolling and horizontal mill are innovative, which are of great engineering significance to manufacture hollow shafts on account of the advantages of avoiding forming defect, reducing roller diameter, improving rolling stability and simplifying mill structure.

Keywords: Flat-knifing cross-wedge rolling; Horizontal cross-wedge rolling mill; Multifunctional rolling mill; Single guide rolling; Hollow shafts rolling 


\begin{tabular}{l|ll|}
\cline { 2 - 2 } 56 & Nomenclature & \\
57 & $\alpha$ & Forming angle \\
58 & $\beta$ & Stretching angle \\
59 & $B$ & Knifing width \\
60 & $L$ & Sizing width \\
61 & $\eta$ & Workpiece reduction \\
62 & $h$ & Wedge height \\
63 & $d_{m}$ & Mandrel diameter \\
64 & $D_{0}, d_{0}$ & Outer and inner diameter of workpiece before rolling \\
65 & $D_{1}, d_{1}$ & Outer and inner diameter of workpiece after rolling \\
66 & $L_{N 1}, L_{F 1}$ & Knifing length of NCWR wedge and FCWR wedge \\
67 & $L_{N 2}, L_{F 2}$ & Stretching length of NCWR wedge and FCWR wedge \\
68 & $L_{N 3}, L_{F 3}$ & Sizing length of NCWR wedge and FCWR wedge \\
69 & $L_{R}$ & Wedge length reduction from NCWR to FCWR \\
\cline { 2 - 4 } &
\end{tabular}


Since hollow shafts have advantages of lightweight structure, low rotating inertia and convenient flaw detection, more and more solid parts are designed to be hollow such as railway axles [1], engine valves [2], and truck shafts [3]. Up to now, these hollow shafts are mainly formed by forging, extrusion and drilling, which result in the waste of material and low production efficiency.

Cross wedge rolling (CWR), a near-net shape metal manufacturing process with high production efficiency and low material consumption, has an extensive application in solid shafts including large-elongated parts (e.g., automobile camshafts, stepped shafts) and die-forging preforms (e.g., engine valves, connecting rods, double-ended spanners) as reviewed by $\mathrm{Hu}$ et al. [4] and Pater et al. [5]. Hu et al. [4] pointed out they have established more than 300 production lines worldwide with an estimated production value of more than $\$ 200$ million per year, and highlighted that the weight of CWR products has over 400,000 tons with an amount of 2 billion pieces per year in China. However, although CWR has been successfully used on solid shafts, it is less common on hollow shafts.

Compared with forging, extrusion and drilling process, CWR of hollow shafts has advantages of high efficiency, not need lubricant and less loading. Researchers have been concerned about its applications. Huo et al. [6] presented a CWR process for highspeed railway axles, and predicted the microstructure and ductile damage at hot forming. Ji et al. [2] proposed to manufacture hollow valve-preforms by CWR, and investigated the influence of process parameters. Yang et al. [3] developed a process of CWR hollow axle sleeve, and studied the elliptical behavior of inner hole. Pater et al. [7] presented a conception of the three-roller cross rolling process of hollow rail axles, and found that the walls of formed steps are thickened. Peng et al. [8] used a multi-wedge CWR without mandrel to produce hollow high-speed railway axle, and reached a conclusion that the double-wedge CWR for large and long thick-walled hollow shafts is feasible. These works are meaningful and have pointed out a new approach to manufacture 
hollow shafts.

To establish a reliable technique for rolling hollow shaft, CWR without mandrel was early proposed and investigated. Bartnicki and Pater $[9,10]$ analyzed the numerical simulation results and found the thinner wall thickness may cause the slipping and flattening of billet, and concluded the three-roller CWR can improve rotation conditions. Urankar et al. [11] proposed a dimensionless crushing parameter to predict forming limit of the hollow products, and the defect of hole expansion was shown in their study. However, CWR without a mandrel has a common shortcoming that its inner hole is unable to be regularly formed because the hole is formed randomly.

A process of CWR with mandrel was proposed to control the dimensions of inner hole, and researches have been done to improve its forming performance. Neugebauer et al. [12] proposed two ways to control the movements of mandrel: fixed or freedom mandrel. Landgrebe et al. [13] modified the typical CWR via adding a drilling mandrel, therefore a hollow shaft can be directly rolled from a solid billet. Shen et al. $[14,15]$ used a compensated mandrel to produce hollow shafts with a variable inner diameter. Recently, Shen et al. [16] based on the volume consistency principle, and established a theoretical model to predict the critical mandrel diameter. However, many of these researches have focused on mandrel design and parameter optimization, but pay less attention to roller modification.

In normalized CWR with mandrel, as shown in Fig.1, although inner hole can be controlled, it brings about the defects of hole expansion and knifing groove [17-20]. Hole expansion exists on the inner hole, while knifing groove on the outer surface. These defects reduce the utilization of materials and increase the cost of post-processing. Ji et al. [17] employed variable stretching angle to avoid hole expansion, but make roller design complicated. In engineering practice, skilled workers generally solve the hole expansion by chamfering knifing-wedge. Actually, both hole expansion and knifing groove occur in the knifing position of rolled shafts. Therefore, modifying the shape of roller on knifing zone is of great significance. 


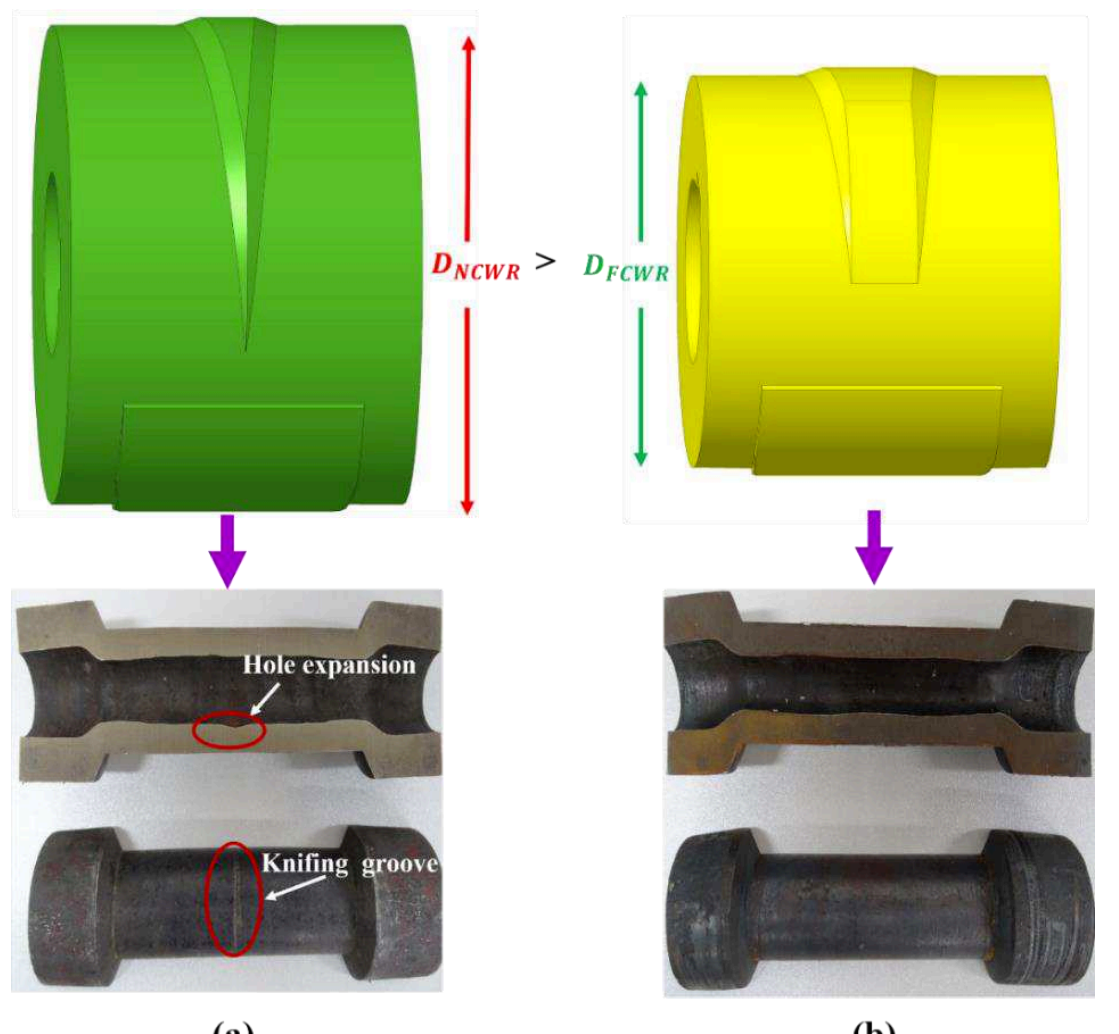

(a)

(b)

Fig. 1 Contrast between two methods for hollow shafts:

(a) normalized CWR; (b) flat-knifing CWR

In this study, a novel flat-knifing cross-wedge rolling (FCWR) with single guide for hollow shafts (Fig.1b) is proposed whereby modifying roller and mill from the base of normalized cross-wedge rolling (NCWR), which takes advantages of avoiding the defects of hole expansion and knifing groove, reducing the diameter of rollers, improving rolling stability and simplifying mill structure.

In order to study the new process systematically, its key points are investigated by numerical simulation and experimental research. Firstly, the new process of FCWR with single guide is described in detail. Secondly, the mathematical model of FCWR roller is established and the length reduction is calculated and visually presented. Thirdly, numerical simulations are conducted to compare the NCWR and FCWR process from the aspects of defect formation mechanisms, workpiece deformation characteristics and influences of new parameter. At last, corresponding physical FCWR experiments are performed to verify the FE results, and the advantages and disadvantages of these improvements are discussed. 


\section{Flat-knifing cross-wedge rolling with single guide}

144

145

146

148

149

\subsection{Novel process principle}

The process principles of normalized cross-wedge rolling (NCWR) with two guides and flat-knifing cross-wedge rolling (FCWR) with single guide are shown in Fig.

2. They have same deform mechanism that a cylindrical hollow billet is deformed into a stepped hollow shaft under the action of roller whereby wedged rollers moving tangentially relative to each other.

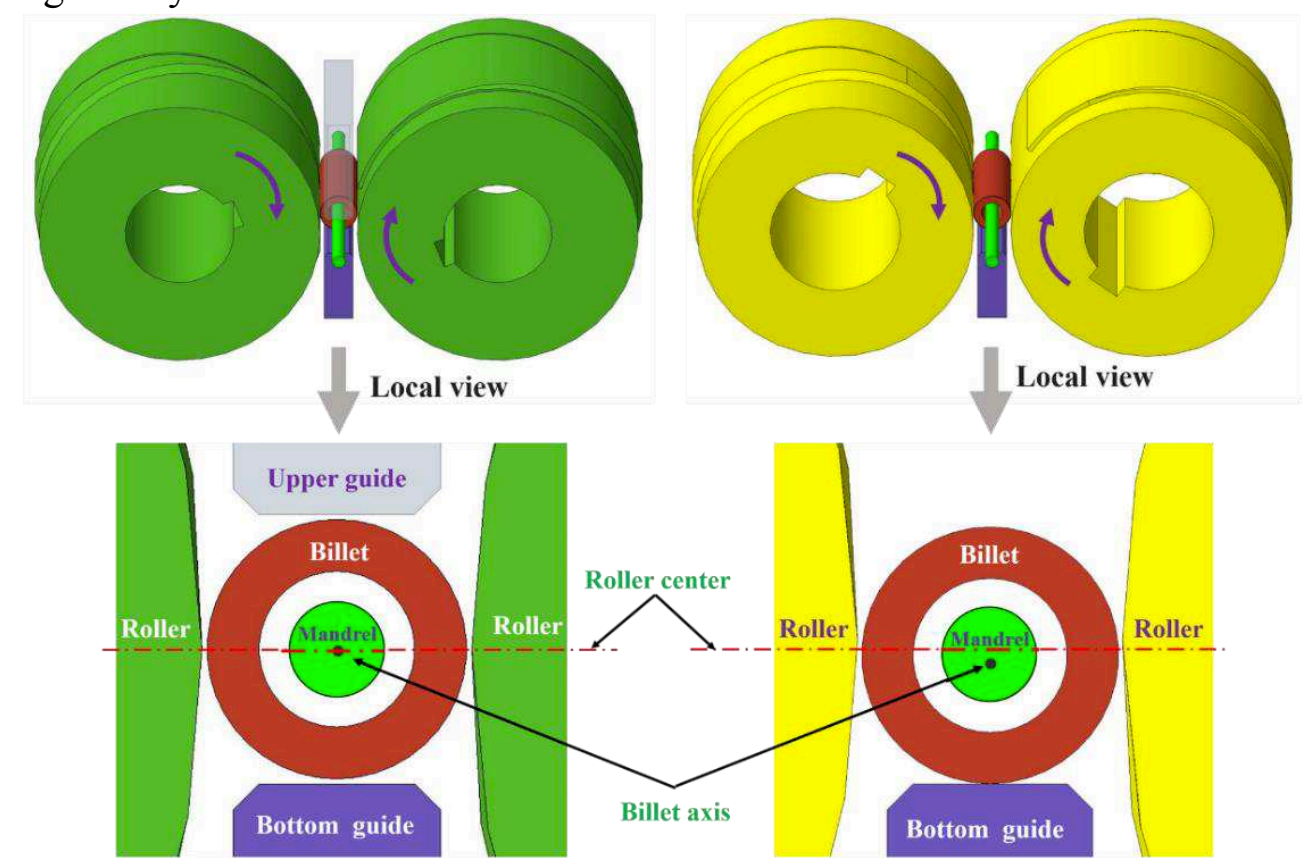

(a)

(b)

Fig. 2 Process principle: (a) NCWR with two guides; (b) FCWR with single guide There are some improvements: 1) the knifing wedge of FCWR roller is flatted, while that of NCWR is sharped; 2) differing from NCWR has a vertical structure, FCWR process changes into a horizontal arrangement that can achieve single guide rolling under gravity; 3) by single guide rolling, FCWR workpiece is steadily restricted into a smaller workspace. As a result, the novel process is estimated has advantages of:

- the defects of hole expansion and knifing groove can be absolutely avoided;

- the diameter of two rollers can be evidently shortened;

- the mill can be simplified into single guide structure;

- The rolling stability can be improved. 


\subsection{New type of horizontal multifunctional mill}

161

In order to achieve the technical objective of single guide rolling, a laboratory mill

162 with a horizontal structure is indispensable. Up to now, the traditional CWR mills

163 commonly have a vertical structure [4, 5, 22], which apparently cannot meet the 164 requirement of this study.

165 Therefore, a new type of rolling mill is invented and constructed by the authors 166 [23]. The freedoms of this mill has been increased by two angle adjusting systems, one 167 radial feeding system, and a synchronous unit (worked by two matched gears). Its 3D 168 model is shown in Fig. 3, the mill is presented in Fig. 4, and the technical specifications 169 are given in Table. 1.

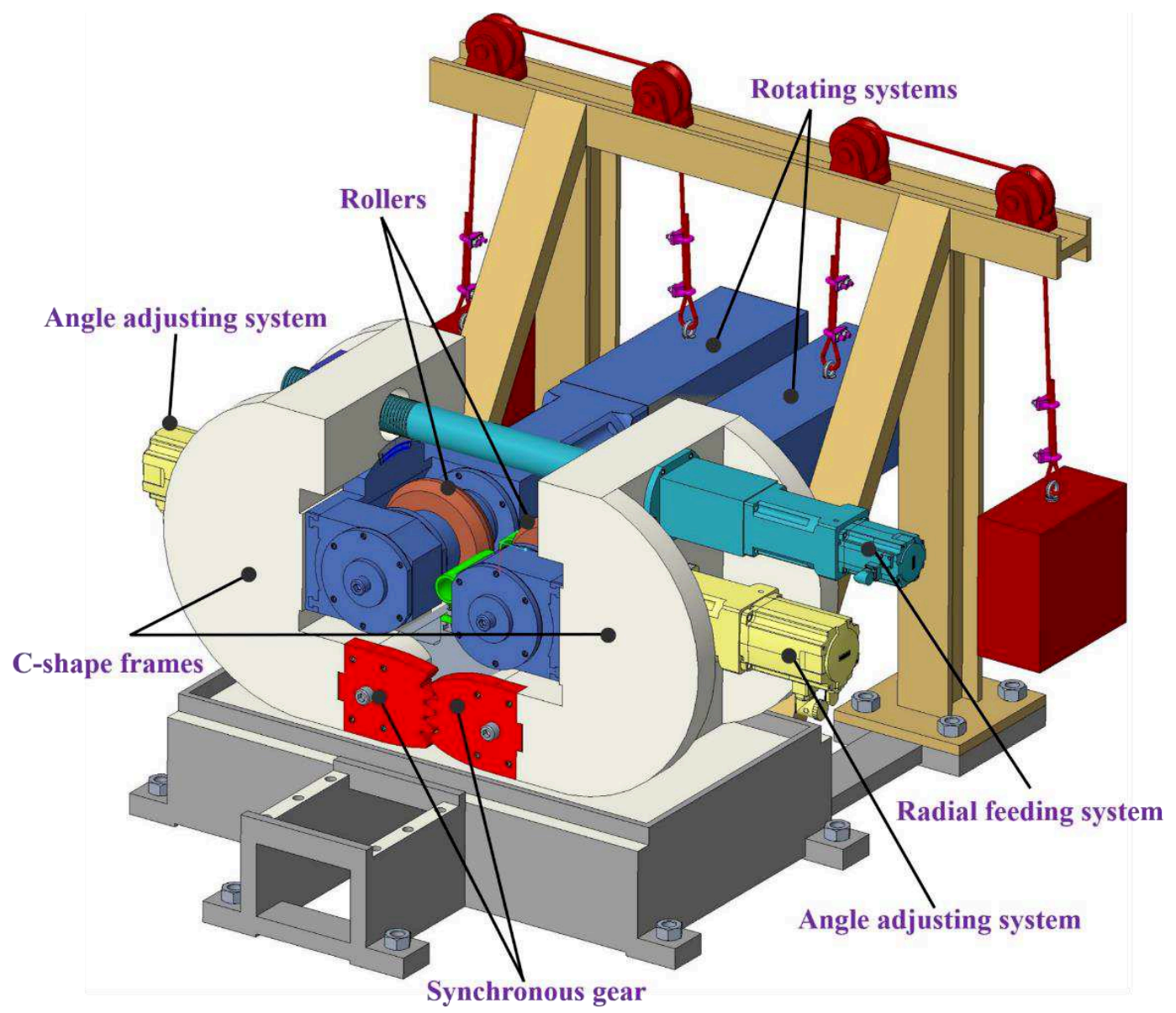

Fig. 3 Geometrical model of the horizontal multifunctional mill [23] 


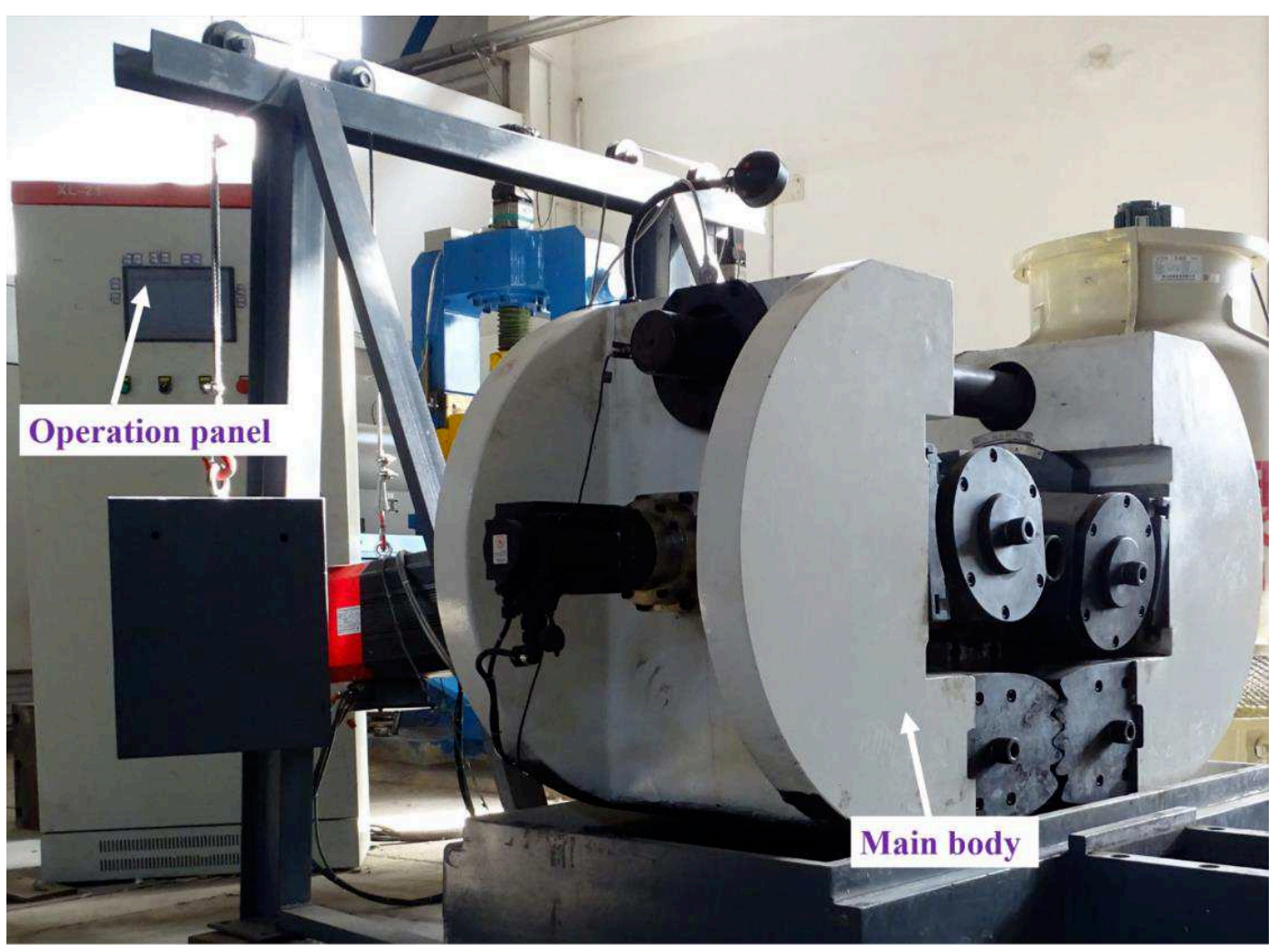

Fig. 4 The constructed horizontal multifunctional mill [23]

Table 1 Technical specifications of the horizontal multifunctional mill

\begin{tabular}{lcc}
\hline Parameter & Unit & Value \\
\hline Power of main rotating motor & $\mathrm{kW}$ & $2 \times 30$ \\
Speed of main rotating & $\mathrm{rpm}$ & $0 \sim 43$ \\
Power of Radial feeding motor & $\mathrm{kW}$ & 3 \\
Speed of Radial feeding & $\mathrm{mm} / \mathrm{s}$ & $1 \sim 5$ \\
Power of angle adjusting motor & $\mathrm{kW}$ & $2 \times 2.3$ \\
Speed of angle adjusting & $\circ / \mathrm{s}$ & $1 \sim 10$ \\
Range of angle adjusting & $\circ$ & \pm 12 \\
Maximum diameter of roller & $\mathrm{mm}$ & 350 \\
Maximum diameter of billet & $\mathrm{mm}$ & 80 \\
Overall dimensions & $\mathrm{m}$ & $1.8 \times 1.7 \times 1.6$ \\
Total power & $\mathrm{kW}$ & 70 \\
Total weight & ton & 5 \\
\hline
\end{tabular}


This mill is characteristic of multiple freedom degree because has several 176 movements of circumferential rotating, radial feeding and angle adjusting, and thus it

177 can be used for different types of laboratory rolling tests such as longitudinal rolling, 178 cross rolling, and skew rolling.

179 All the motions of this mill are directly driven by servo motors that mill structure 180 is compact. As signed in Fig.3, two C-type frames are used to enchence mill strength, 181 the automation system is controlled by a accurate servo drive which programed in PLC

182 language. All these features may take this type of mill advantages of compact structure,

183 high strength and high precision, so that it can be expected to be industrially applied as 184 thread rolling mill, ball rolling mill and CWR mill.

\subsection{New type of flat-knifing roller}

Roller modification is a main innovation of this paper. In the hope of mathematically describing the FCWR roller in detail, both the geometrical models of FCWR and NCWR roller are designed and shown in Fig. 5 with a plane layout way.

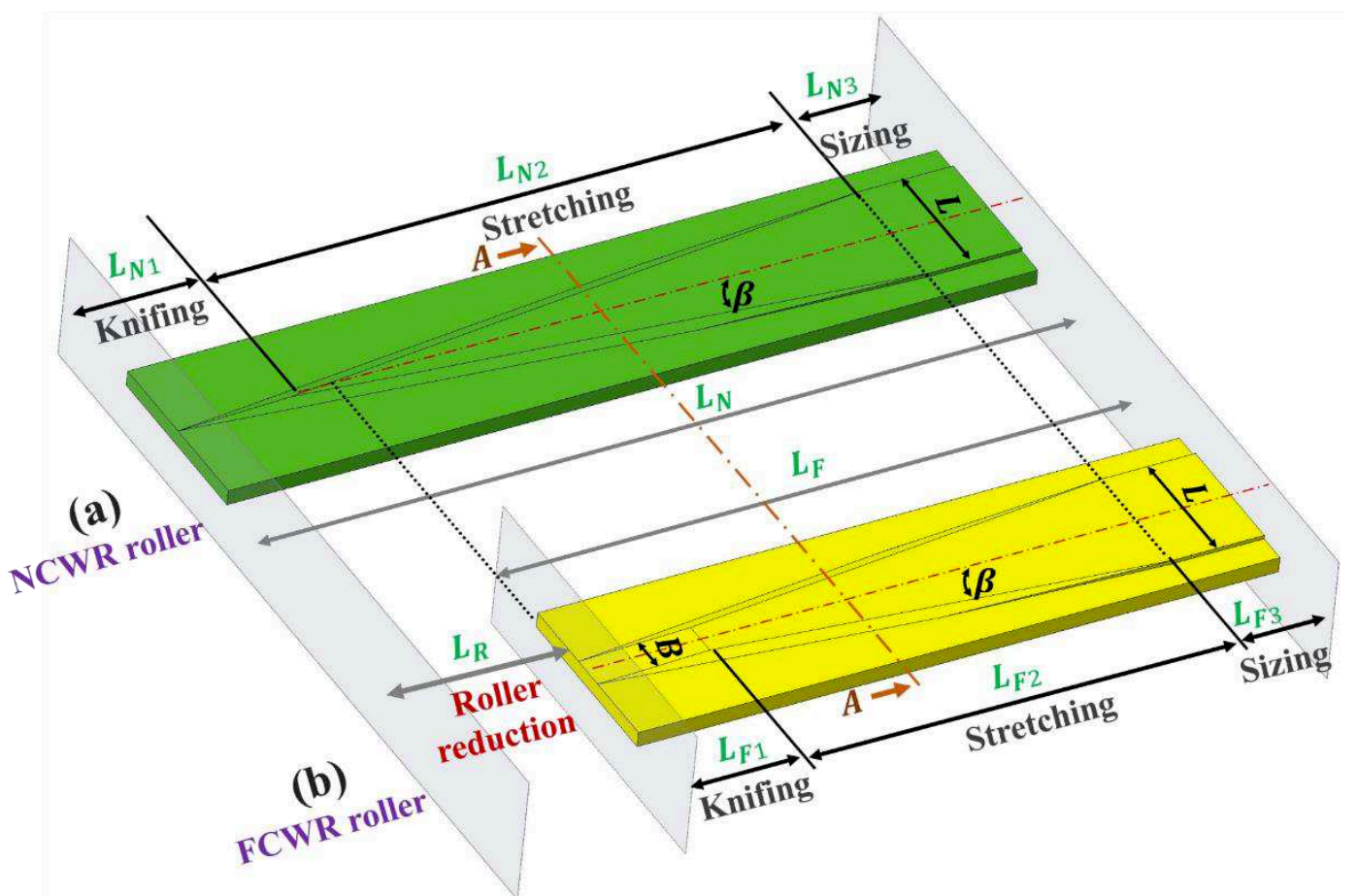

Fig. 5 Configuration and major parameters of NCWR and FCWR roller

191 NCWR roller is designed as a V-shaped wedge, while FCWR roller is a flat-wedge with 
a width of $B$. Further, the FCWR roller only changes the wedge shape in the knifing

193 zone, and their configurations are identically divided into three sections as knifing zone, 194 stretching zone and sizing zone. Fig. 6 shows that their contact models (extracted from 195 the A-A view of Fig. 5) between roller, mandrel and workpiece of FCWR and NCWR 196 roller are exactly same on stretching zone. To make an analysis, on the one hand, the main deformation of FCWR rolling is occurred in stretching zone, where FCWR has the same contact model with NCWR. On the other hand, FCWR process have the same sizing zone with NCWR. As a conclusion, these modifications have not changed the process parameters form the NCWR, so that both NCWR and FCWR may have the same process parameters such as forming angle $\alpha$, stretching angle $\beta$ and mandrel 202 diameter $d_{m}$.

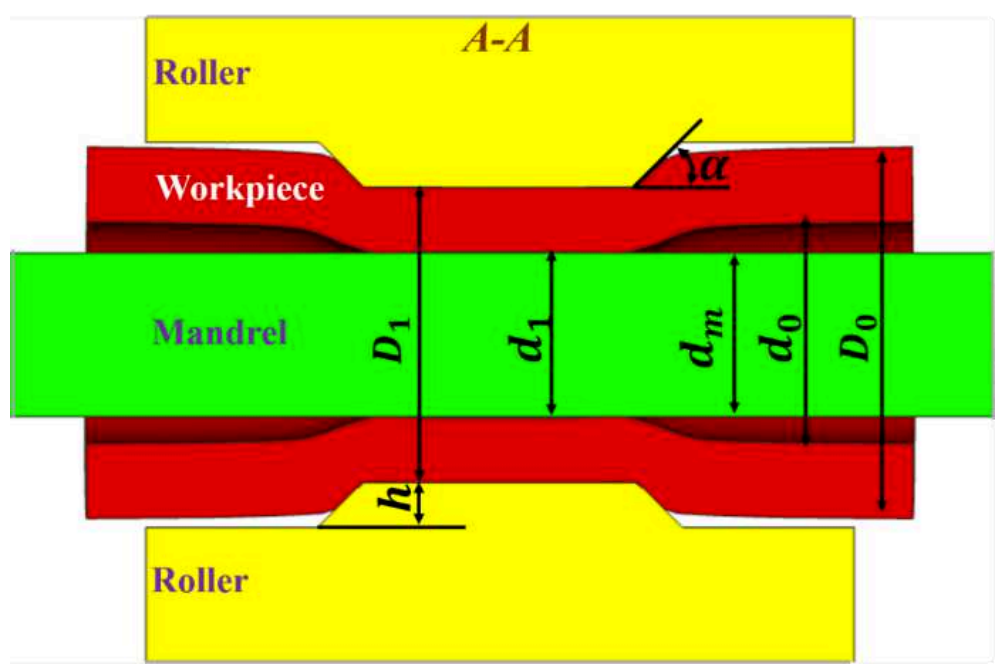

Fig. 6 Contact model of roller, mandrel and workpiece at the stretching stage

In order to mathematically compare FCWR and NCWR roller, the calculation of wedge length is a basic work, which need to be undertaken primarily.

At the knifing zone, notwithstanding the different geometries, the wedge lengths of FCWR and NCWR roller are equally formulated as Eq. 1, where $h$ is the height of wedge, $\alpha$ is forming angle, and $\beta$ is the stretching angle.

$$
L_{N 1}=L_{F 1}=h \cot \alpha \cot \beta
$$

At the stretching zone, because the initial position of FCWR wedge have a straight 211 section, $L_{N 2}$ is obviously longer than $L_{F 2}$, and they are respectively calculated by Eq. 2 
212 and Eq. 3, where $L$ represents the sizing width (signed in Fig. 5) and $B$ represents the

213 knifing width.

Owing to the geometries at sizing zone of NCWR and FCWR are exactly same,

217 they have same sizing length which can be formulated by Eq. 4, where $D_{0}$ and $D_{1}$ are 218 the outer diameter of the workpiece before and after rolling.

$$
L_{N 3}=L_{F 3}>0.25 \pi\left(D_{0}+D_{1}\right)
$$

Because the length of each zone is determined through the above equations, the 221 length reduction $L_{R}$ can be calculated by Eq. 5 .

$$
L_{R}=0.5 B \cot \beta
$$

For a purpose of a more intuitive comparison of the wedge length of roller, their 224 formulas are summarized in Table 2. It can be concluded that the lengths of knifing 225 wedge and sizing wedge of NCWR and FCWR roller are equal in value, while FCWR 226 stretching length is shorter than that of NCWR.

227 Table 2 Mathematical comparison of the wedge lengths of NCWR and FCWR roller

\begin{tabular}{cccc}
\hline Type & \multicolumn{1}{c}{ NCWR } & FCWR & Comparison \\
\hline & $L_{N 1}=h \cot \alpha \cot \beta$ & $L_{F 1}=h \cot \alpha \cot \beta$ & $L_{N 1}=L_{F 1}$ \\
Equation & $L_{N 2}=0.5 L \cot \beta$ & $L_{F 2}=0.5(L-B) \cot \beta$ & $L_{N 2}>L_{F 2}$ \\
& $L_{N 3}=0.25 \pi\left(D_{0}+D_{1}\right)$ & $L_{F 3}>0.25 \pi\left(D_{0}+D_{1}\right)$ & $L_{N 3}=L_{F 3}$ \\
\hline $\begin{array}{c}\text { Length } \\
\text { reduction }\end{array}$ & & $L_{R}=0.5 B \cot \beta$ & \\
\hline
\end{tabular}

In order to visually reveal the relationship between wedge-length reduction and process parameters, a three-dimensional graphic have been drawn as expressed in Fig.

230 7. The length reduction $L_{R}$ is only related to stretching angle $\beta$ and knifing width $B$, 231 which increases with the increase of $B$ and $\beta$ in range of $200 \sim 800 \mathrm{~mm}$. Take an example 232 of the roller used in the experiment of later study: $\beta=2^{\circ}, B=18 \mathrm{~mm}$, its wedge length 


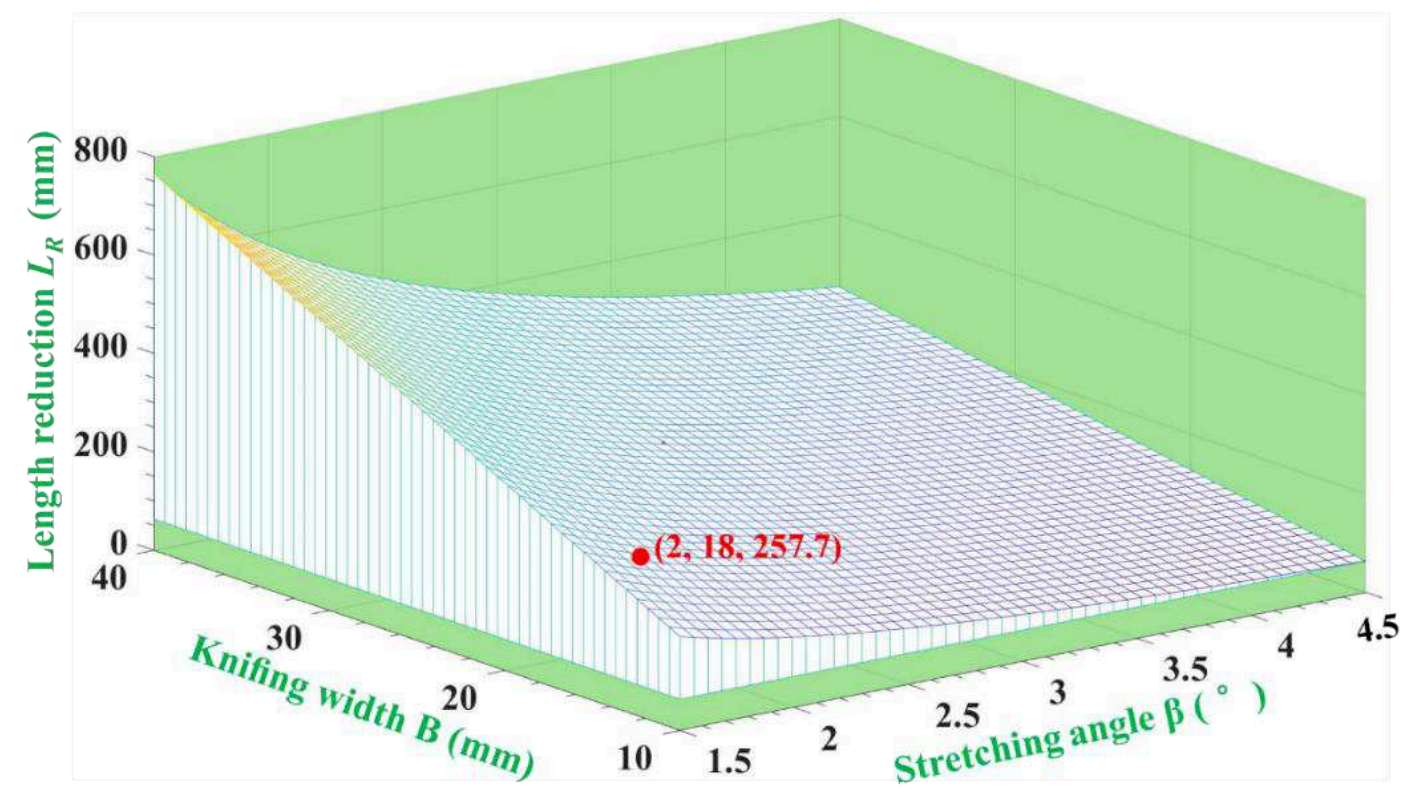

Fig. 7 Relationship between wedge-length reduction and process parameters

\section{Parameter ranges and research schemes}

Considering process parameters will directly affect whether this novel process is successful or not, the ranges of major parameters are discussed and summarized based on the previous research of NCWR hollow shafts $[16,17,24]$.

(1) The workpiece reduction $\eta$. Workpiece reduction reflects deformation degree and the flattening of workpiece. In the case of hollow billet with thin wall, the large $\eta$ make the rolling piece undergo serious flattening deformation and then the rolling status is instability, so that the products become elliptical finally. In addition, when the hollow

244 billet has a thick wall, in this case the rolled piece has a better resistance to flattening

245 deformation, the roundness of the rolled products is improved under the condition of a 246 larger $\eta$ because of the good flow of axial metal. The workpiece reduction $\eta$ is expressed 247 and ranged as Eq. 6.

$$
0.2<\eta=\frac{D_{0}-D_{1}}{D_{0}}<0.4
$$

(2) The forming angle $\alpha$. Forming angle is an important roller parameter, which 250 directly determines the contact surface of of forming area and then affects the metal 
251 flow. In the reason that hollow billet is more prone to elliptical and then the axial flow 252 of the metal may become worse, the forming angle of the hollow shafts rolling is 253 generally greater than that of solid shafts, whose value is usually derived as follows:

$$
30^{\circ}<\alpha<50^{\circ}
$$

(3) The stretching angle $\beta$. Stretching angle is another important tool parameter.

256 Increasing its value is beneficial to decrease the length of roller but enlarges the tangential deformation of the workpiece, as a result, it is easy to cause oval deformation.

258 Therefore, the stretching angle for hollow shafts is generally smaller than solid shafts, 259 its range is:

(4) The mandrel diameter $d_{m}$. The mandrel is used to control the shapes and 262 dimensions of inner hole. When its diameter is too small, mandrel will unable to contact 263 inner hole and out of service. And when its value gets too large, it makes the rolling 264 wall thin seriously and wall deformation become severe, thus billet cannot rotate 265 normally. Its value is usually designed as Eq. 9, in which $d_{0}$ is the initial diameter of 266 inner hole.

$$
0.5 d_{0}<d_{m}<0.9 d_{0}
$$

(5) The knifing width $B$. Knifing width is a new parameter which only exists on FCWR roller. On the basis of previous explorations (discussed in later sections), larger knifing width allow for less length of wedge but increase workpiece ellipticity, rolling 271 force, and rotating torque. Its value is generally selected as:

$$
10 \mathrm{~mm}<B<40 \mathrm{~mm}
$$

On the basis that the selection ranges of main parameters have been determined, a research scheme combined FE simulations and experimental tests has been worked out as demonstrated in Table 3. The FE simulation is adopted to compare the distinction on

276 NCWR and FCWR from the aspects of defect mechanisms, deformation characteristics 277 and influences of new parameter. Correspondingly, the physical FCWR tests are conducted to verify the FE results and reveal the advantages and disadvantages of 
Table 3. Research schemes and parameter values

\begin{tabular}{ccccc}
\hline $\begin{array}{c}\text { Parameter } \\
\text { symbol (unit) }\end{array}$ & $\begin{array}{c}\text { Billet inner diameter } \\
d_{0}(\mathrm{~mm})\end{array}$ & $\begin{array}{c}\text { Mandrel diameter } \\
d_{m}(\mathrm{~mm})\end{array}$ & $\begin{array}{c}\text { Knifing width } \\
B(\mathrm{~mm})\end{array}$ & Method \\
\hline NCWR & 30 & none & none & FE \\
& 30 & 22 & none & FE \\
FCWR & 30 & none & 18 & FE, Test \\
& 30 & 22 & $14,18,22$ & FE \\
& $30,28,26,24$ & $22,20.5,19,17.6$ & 18 & Test \\
\hline
\end{tabular}

Besides, $D_{0}=50 \mathrm{~mm}, \alpha=45^{\circ}, \beta=2^{\circ}, h=6 \mathrm{~mm}, T=1050^{\circ} \mathrm{C}, d_{m} / d_{0}=0.73$.

\section{Numerical simulations of NCWR and FCWR with single guide}

\section{$283 \quad 4.1$ Finite element modeling}

284 Preliminary feasibility study was done by numerical simulations. Both NCWR and 285 FCWR finite element (FE) models were established. It should be pointed out that, the 286 FE model of NCWR and FCWR only changed the rollers while other parameters such 287 as billet dimensions, rolling temperature and mandrel dimensions stayed the same. The 288 FE scheme and parameter were carried out according to Table 3.

289 The FE projects were performed in Simufact.Forming software, which has been 290 successfully employed in numerical analysis of CWR process [25, 26] and skew rolling 291 process [27, 28], and their FE results have a good agreement with experimental results.

292 The FE projects of NCWR and FCWR with single guide were modeled as Fig. 8 shows.

293 Both the geometric models of NCWR and FCWR were consisted of two rollers, one 294 guide, one mandrel and one workpiece. The positional relationships between each part 295 were set up as marked in Fig. 2. The workpiece axis was downwardly offset from roller 296 centre with a $3 \mathrm{~mm}$ distance. 


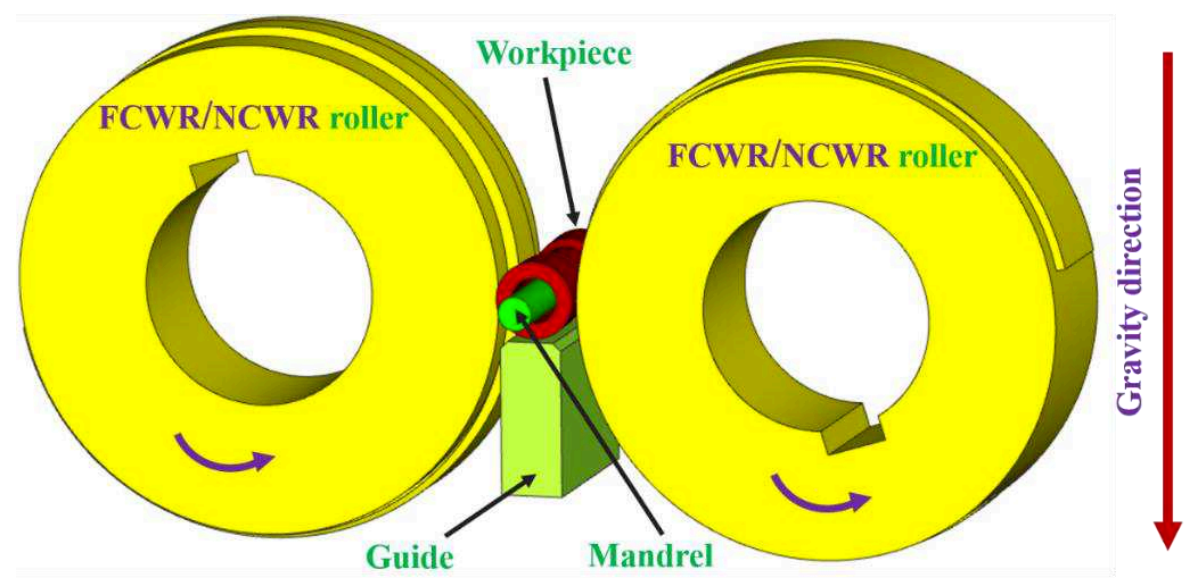

Fig. 8. FE projects of FCWR and NCWR with single guide.

The billet is C45 steel rod with an outer diameter of $50 \mathrm{~mm}$, an inner diameter of

$29930 \mathrm{~mm}$ and a length of $100 \mathrm{~mm}$. Its material data were taken from Simufact.Material.

300 The properties (i.e., density, Young's modulus and Poisson's ratio) were set as default.

301 The flow stress of C45 steel was defined by Eq. 11, in which $\sigma_{F}$ is the flow stress (MPa), $302 \varphi$ is the eff ective strain $(-)$ and $T$ is the temperature $\left({ }^{\circ} \mathrm{C}\right)$ :

$$
\sigma_{F}=2589.85 e^{-0.003125 T} \varphi^{(0.00004466 T-0.10127)} e^{(-0.000027 T+0.0008183) / \varphi} \dot{\varphi}^{(0.00015 T-0.002749)}
$$

The friction coefficients between tools and workpiece were modeled by Shear model (two rollers were 0.8, guide and mandrel were 0.2. [28] The temperature of tools (rollers, guide and mandrel) was constantly maintained at $300{ }^{\circ} \mathrm{C}$ [28]. The initial temperature of workpiece was $1050^{\circ} \mathrm{C}$ and the coefficient of heat transfer between tools and workpiece was $10 \mathrm{~kW} / \mathrm{m}^{2} \mathrm{~K}$ [28]. Besides, the mesh of billet was created by ringmesh mesher, whose element size equals to $1.4 \mathrm{~mm}$, and will be automatically reconstruected if the eff ective strain increases by 0.4 [28]. Both the NCWR and FCWR

311 rollers rotated at a same speed of $6 \mathrm{rpm}$.

\subsection{Comparison of forming defects}

Four FE results with the parameters of $D_{0}=50 \mathrm{~mm}, d_{0}=30 \mathrm{~mm}, \alpha=45^{\circ}, \beta=2^{\circ}$,

$314 d_{m}=22 \mathrm{~mm}$ and $B=18 \mathrm{~mm}$ was extracted from the software postprocessor and shown in 315 Fig. 9. With the help of the numerical simulation, the shape of rolling workpiece can be 316 acquired at every moment. 


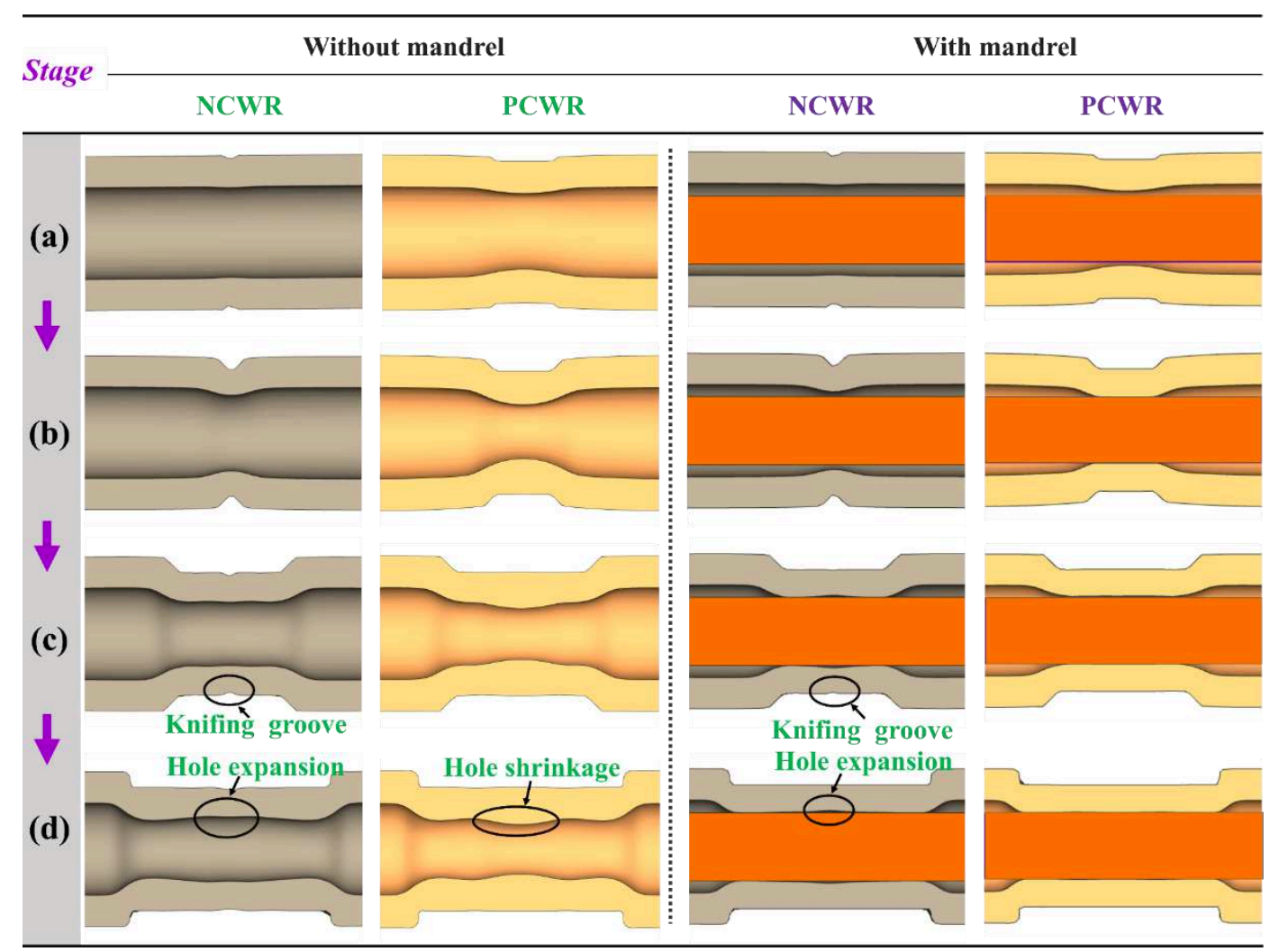

Fig. 9 FE results of NCWR and FCWR: (a) middle of knifing stage; (b) end of knifing stage; (c) middle of stretching stage; (d) end of stretching stage

At the middle of knifing stage, all the workpieces are not contact with mandrel.

But at the end of knifing stage, there is a difference that FCWR workpiece contacts with

mandrel while NCWR does not. Considering the values of mandrel diameters are the same, it can be concluded that, the radial deformation of inner hole in FCWR process is more serious than that in NCWR during the whole knifing stage.

The defects of hole expansion and knifing groove primitively appear on the NCWR shafts at the middle of stretching stage regardless of whether it has mandrel or not (Fig.9c). But in the case of FCWR shafts at this stage, these defects are completely absent. Inversely, there is a hole shrinkage on the FCWR shaft without mandrel. As a

328 result, we can get the FE conclusion that: 1) no matter with or without mandrel, NCWR 329 rolled shafts universally have the defects of hole expansion and knifing groove; 2)

330 FCWR process without mandrel have a defect of hole shrinkage; 3) the FCWR process 331 with mandrel has a good geometric accuracy on outer and inner surface. The conclusion 332 optimistically verifies the technological assumptions, as a result, the FCWR with 
mandrel was adopted on hollow shafts forming in later studies.

\subsubsection{Hole expansion}

Since hole expansion is a major defect in this study, it is necessary to reveal its formation mechanism from aspects of contact surface, loading states and the shape of inner hole (Fig. 10).

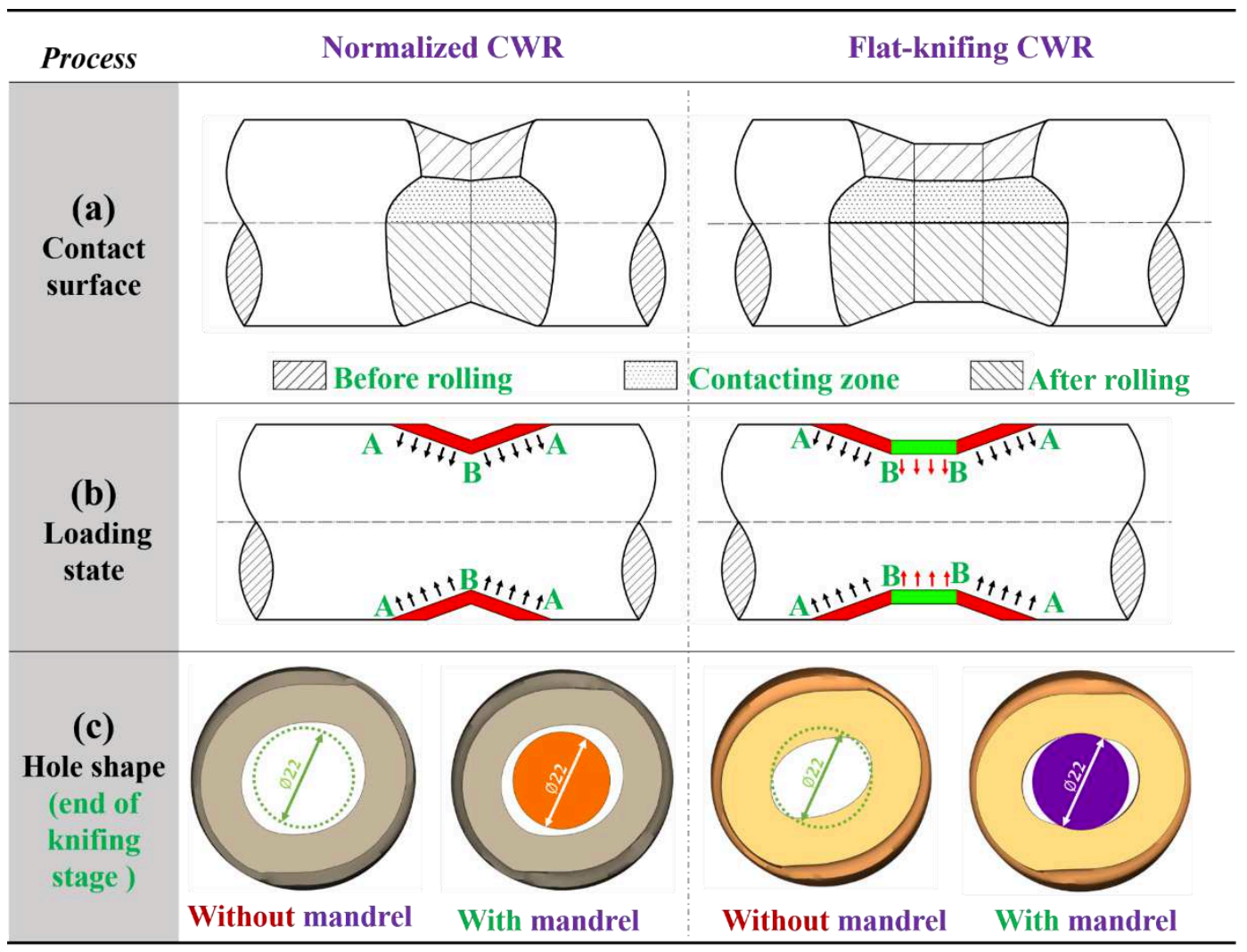

Fig. 10 Formation mechanism of hole expansion (end of knifing stage): (a) contact surface; (b) loading states; (c) hole shape

The contact surface of workpiece was drawn by Boolean subtraction operation in

341 CAD software, which has indicated the different of deformation morphology between 342 NCWR and FCWR. As shown the Fig. 10a, under the same forming angle $\alpha$ and 343 stretching angle $\beta$, the main difference between NCWR and FCWR contact surface is 344 that there is a rectangle contacting zone on the middle of FCWR workpiece.

345 Based on the drawn contact surface, the loading states can be acquired as Fig. 10b 346 shows. At the NCWR knifing stage, because AB and BA segments individually produce 347 a axial component on the side of knifing position, the inner hole is tensioned in axial 
direction and then expanded radially. But in FCWR process, the added BB segment

349 provides a radial force during the knifing stage that promotes the radial flow of the 350 metal, and thus the inner hole is shrunk. Eventually, FCWR hole contacts with the 351 mandrel while NCWR does not (Fig. 10c).

352 In short, FCWR process has an added radial force during knifing stage, which is 353 helpful to the radial flow of the metal and then shrink the inner hole, so that the defect 354 of hole expansion can be avoided in principle.

\subsubsection{Knifing groove}

Another defect concerned about in this study is the knifing groove, which typically appears on the CWR shafts regardless of whether they are hollow or solid $[18,19]$. According to engineering practice, this defect can be avoided via chamfering the knifing-wedge. Obviously, this method cannot solve this defect at design stage. The geometric appearances of NCWR and FCWR workpiece are compared in Fig. 11.

(a)
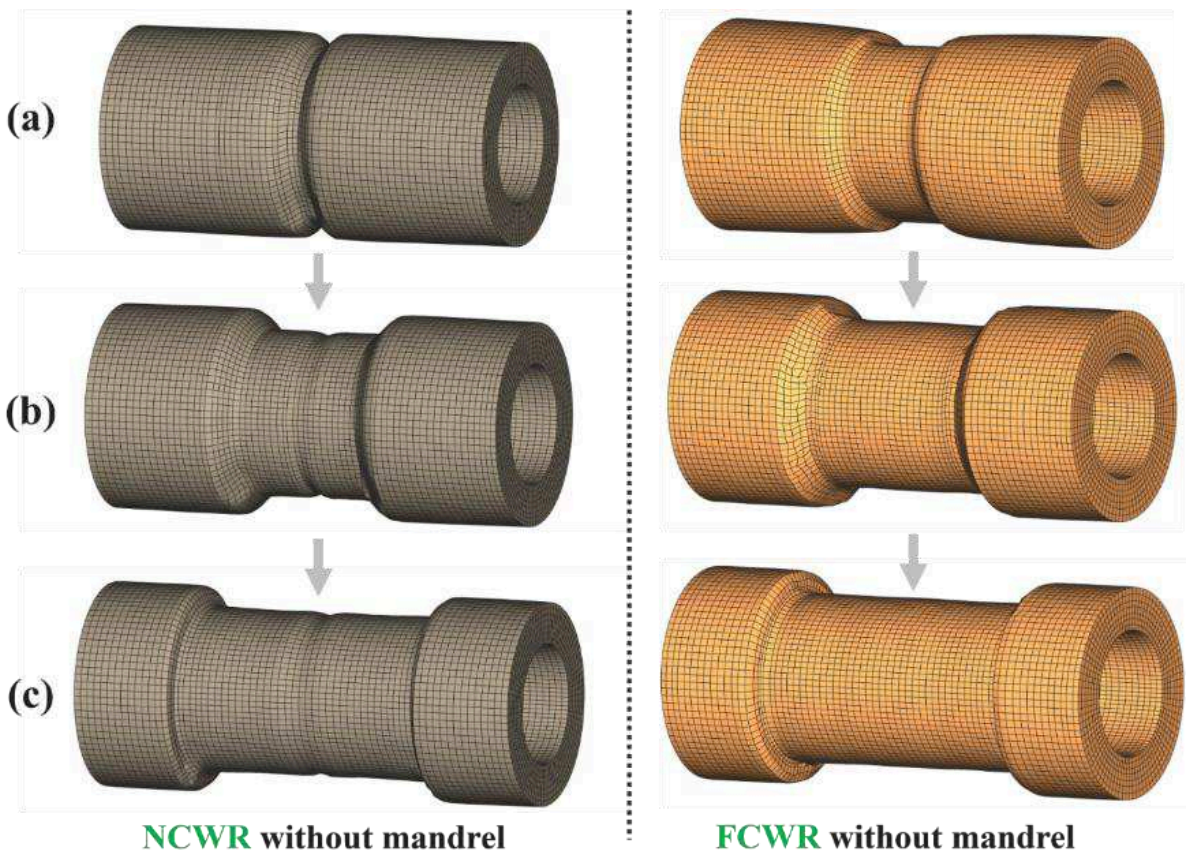

Fig. 11 Geometry comparison between NCWR and FCWR workpiece: (a) end of knifing stage; (b) middle of stretching stage; (c) end of stretching stage

The knifing groove initially appears on the NCWR shaft at the end of knifing stage

364 and then remains until the end. It can be explained that deformation concentration exists on NCWR knifing area which makes the metal of surface undergo a severe local 
deformation. As a result, a groove appears on the knifing position. When it comes to stretching and sizing stage, this defect is hard to be resolved because the height of wedge is constant. In the FCWR process, there is a flat segment BB existing on the middle as Fig. 10b shows, which can avoid the concentrated deformation that the defect of knifing groove does not appeared fundamentally.

\subsection{Effect of new parameter}

\subsubsection{Hole ovality}

The novel process introduces a new process parameter named knifing width $B$.

374 Since it has an influence on the ovality of inner hole, an observation section selected 375 from the axial centre of the workpiece are contrastively compared in Fig 12, which 376 demonstrates that, as the knifing width $B$ increases, the ovalization of inner hole 377 becomes serious.

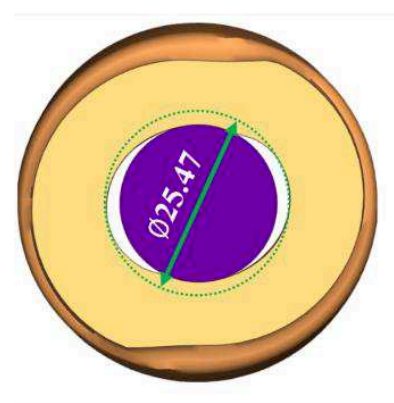

(a) $B=14 \mathrm{~mm}$

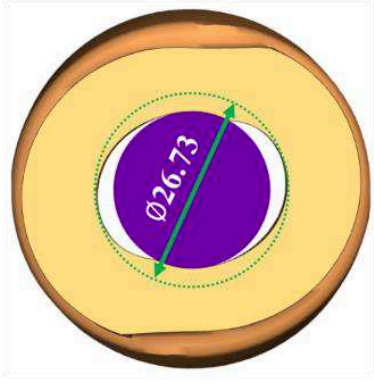

(b) $B=18 \mathrm{~mm}$

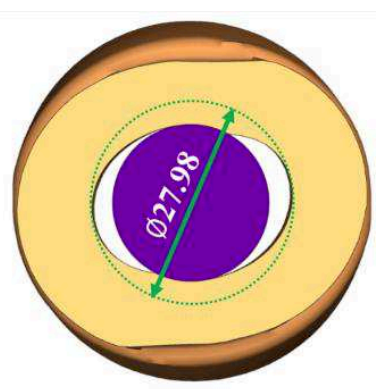

(c) $B=22 \mathrm{~mm}$

Fig. 12 Relationship between knifing width and hole ovality (end of knifing stage)

The ovality of inner hole has negative effect on rolling stability. When the ovality of inner hole is too large, the radial deformation of workpiece will be unstable. Under

381 this situation, even if rollers are rotating normally, the slipped billet cannot rotate 382 regularly. Hence, considering elliptical hole is bad for rolling stability, the value of 383 knifing width should not be too large.

\subsubsection{Rolling force and rotating torque}

Rolling force in the radial direction and rotating torque are the basic data of rolling equipment, which directly determine the capacity of mill and can be predicted by FE 
results as shown in Fig. 13.
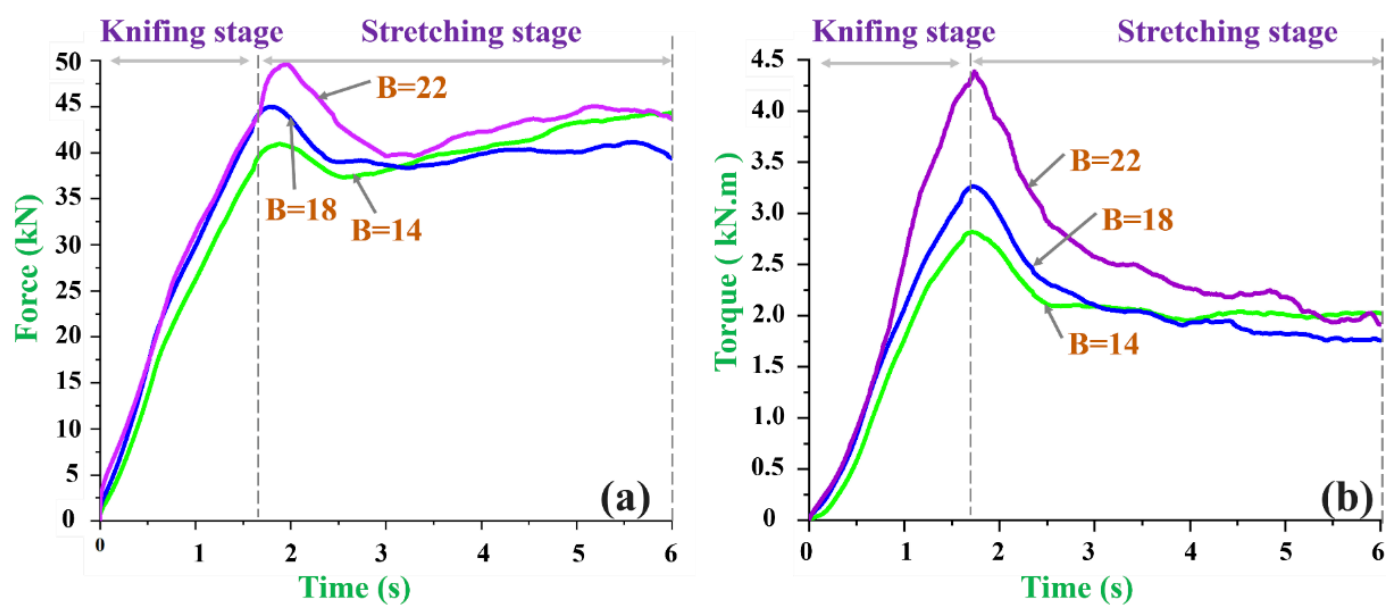

388 Fig. 13 Relationship between knifing width, (a) rolling force, and (b) rotating torque

The trends of rolling force and rotating torque are similar. Both rolling force and rotating torque gradually increase at the knifing stage and then decrease at the beginning

391 of stretching stage. The maximum values of rolling force and rotating torque 392 concurrently appear at the end of knifing stage. Significantly, the knifing width has an 393 effect on the maximum values of rolling force and rotating torque. With knifing width $394 B$ increases, the maximums of rolling force and rotating torque rise as well.

395 Based on above analysis, it can be concluded that large knifing width deteriorates 396 the ellipse of hole and increases rolling force and rotating torque.

\subsection{Formation of the inner hole}

The formation of inner hole is a critical problem of hollow shafts rolling, which 399 directly influences the forming accuracy and the rolled-wall performance. A cross400 section is selected from the axial center of workpiece and observed at different rolling 401 stages as Fig. 14 shows. 


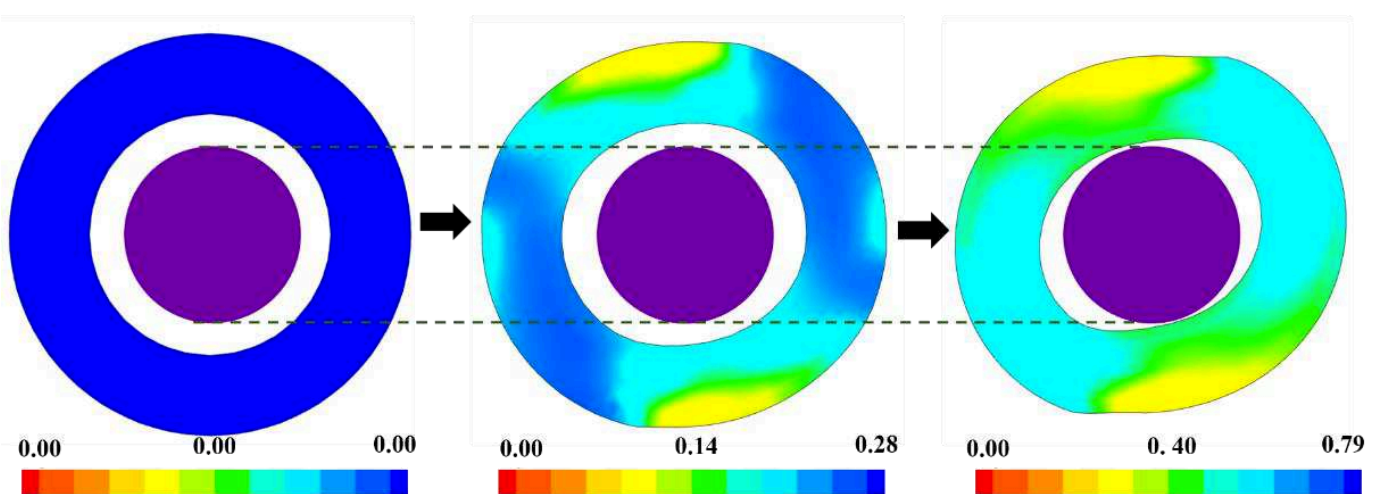

(a)

(b)

(c)

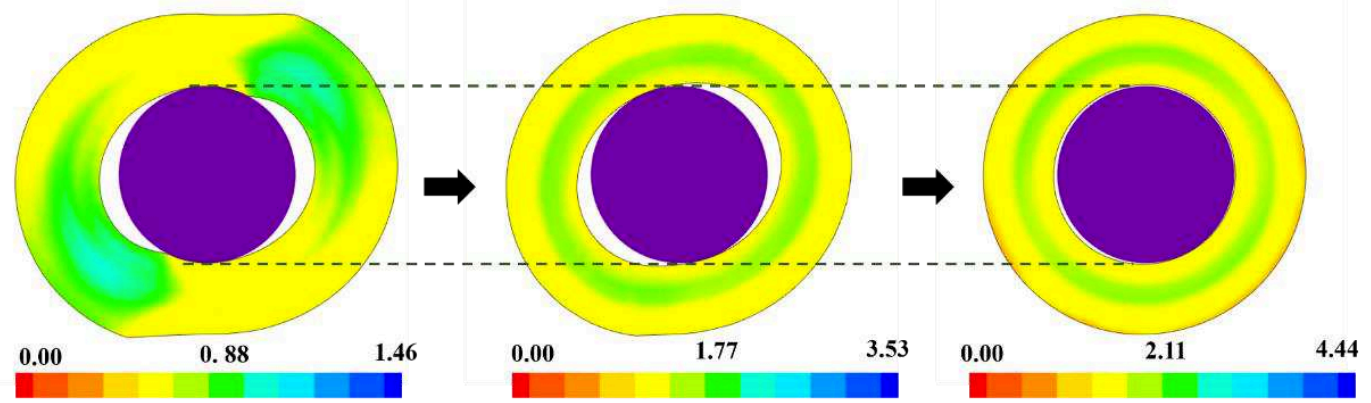

(d)

(e)

(f)

403 Fig. 14 Formation of the FCWR hole (with strain distribution): (a) initial status; (b) 404 begin of workpiece flattening; (c) begin of mandrel contacting; (d) begin of hole sizing; 405 (e) middle of hole sizing; (f) end of hole sizing

406 Because mandrel diameter $d_{m}$ is only 0.73 times of billet hole diameter $d_{0}$ as 407 mentioned in Table 3, the mandrel is away from the inner hole and out of work at the 408 initial stage. However, as rolling process goes on, the inner hole becomes elliptical and 409 then workpiece is beginning to contact the mandrel. Latterly, under the double action 410 of mandrel and rollers, the ovality of inner hole becomes small and small and finally 411 growth into round.

412 The strain distribution of the workpiece is also obtained in Fig. 14. Initially, the 413 billet has local strain at the contacting zone with a small value. But at the hole sizing 414 stage, both the outer and inner of billet undergo a large strain with a value approximate 415 1.7, which have demonstrated an important advantage of FCWR with mandrel - the 416 wall of workpiece is rolled by external roller and internal mandrel that the properties of 417 rolled wall can be improved effectively. 


\section{Experiments of FCWR with single guide}

\subsection{Rolling experiments}

The experiments of FCWR hollow shafts with single guide were performed at University of Science and Technology Beijing in the new type of horizontal mill. Experimental tools consisted of two FCWR rollers, several mandrels and one guide as shown in Fig. 15.

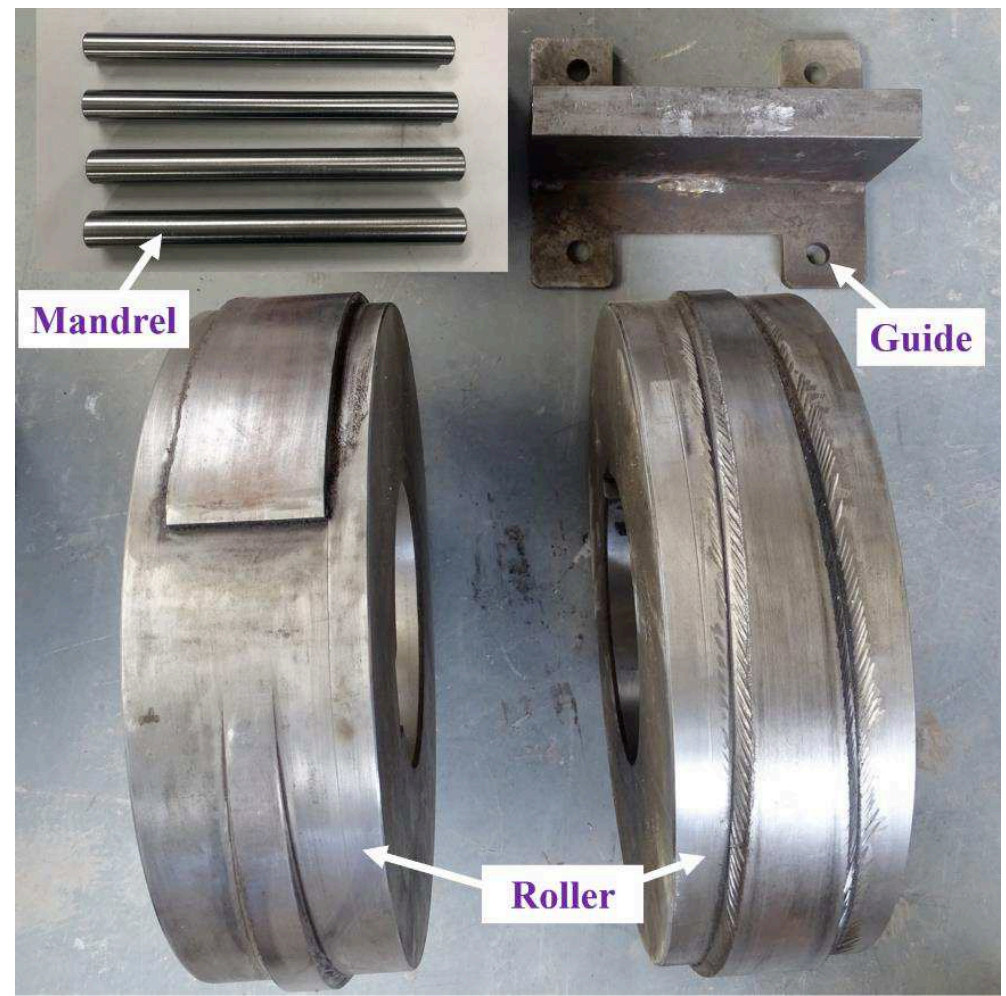

Fig. 15 Tools for FCWR experiments with single guide for hollow shafts

The process parameters of physical experiments corresponded to those of numerical simulations as shown in Tab.3. The guide was mounted between two rollers and downwardly offset from roller centre line with a $28 \mathrm{~mm}$ distance.

The rolling experiments was conducted as Fig. 16 shows. Prior to the rolling, the billet was preheated to $1050{ }^{\circ} \mathrm{C}$ in an electric tube furnace and then immediately transferred to the mill. During the rolling stage, the billet was rotated and deformed under the action of rotating wedges of rollers. After the rolling, the rolled product laid on the top of the guide and then hollow shaft was gained. 

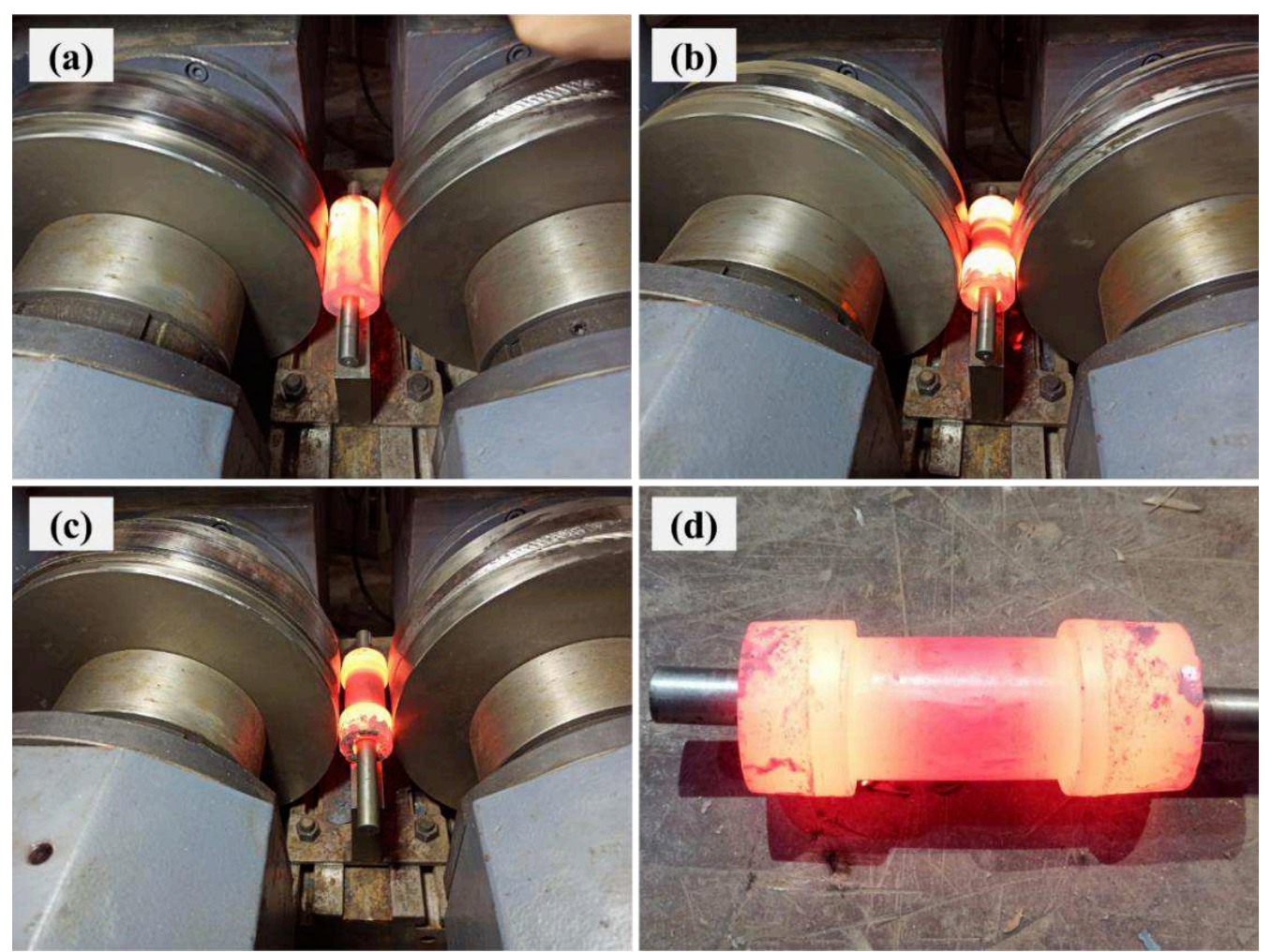

Fig. 16 FCWR rolling experiments in horizontal multifunctional mill with single guide: (a) beginning; (b) rolling stage; (c) ending stage; (d) rolled hollow shaft

By the FCWR tests, it can be observed that the workpiece was rolled stably, which

436 has verified the feasibility of the FCWR process and new horizontal multifunctional 437 mill. The produced hollow axles of FCWR rolling tests were cut and shown in Fig. 17a, 438 and its shot peening produts are shown in Fig. 17b. These hollow shafts are free from 439 the typical defects of hole expansion and knifing groove. However, it raises a new 440 question that the rolled shaft cannot be automatically ejected from the mill that a manual 441 transfer is needed.
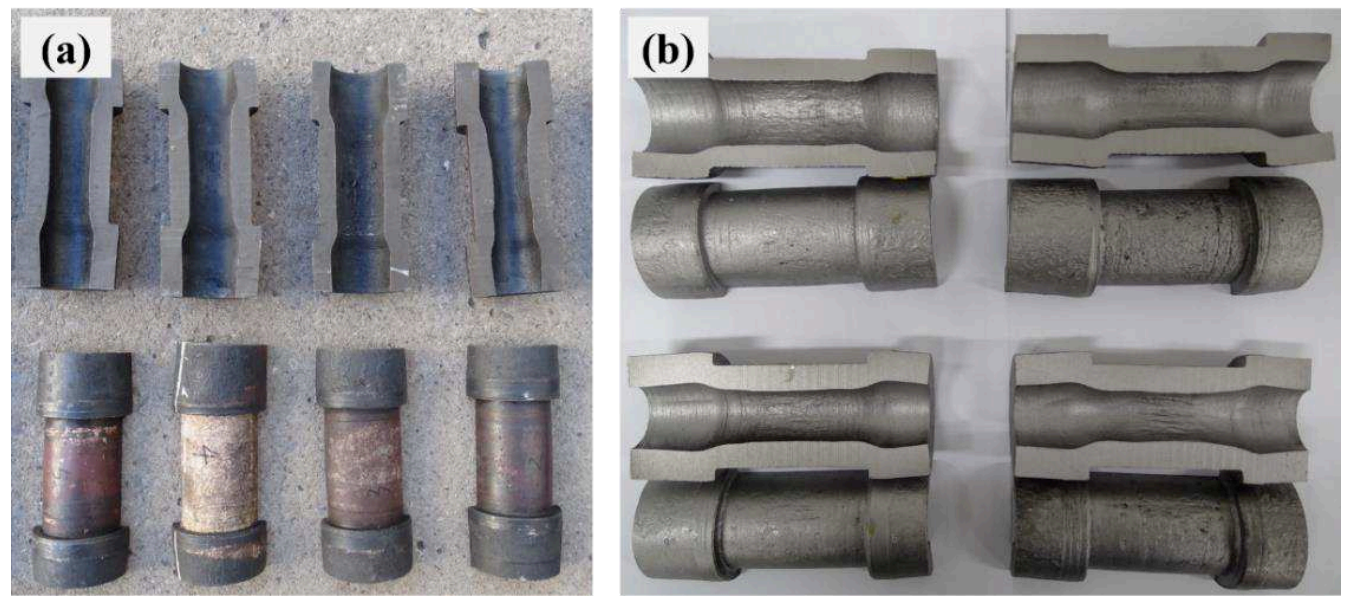

Fig. 17 The FCWR produced hollow shafts: (a) initial status; (b) after shot peening 


\subsection{Results and Discussion}

444

445

448

\subsubsection{Validating of the FEM results}

A verification method of geometric comparison is employed in this study. The geometries of inner holes are compared to verify the FEM results in consideration of its shapes are related to the flow behavior of material, rolling temperature, friction state and so on. Two groups of experiments including without and with mandrel are compared in Fig. 18.

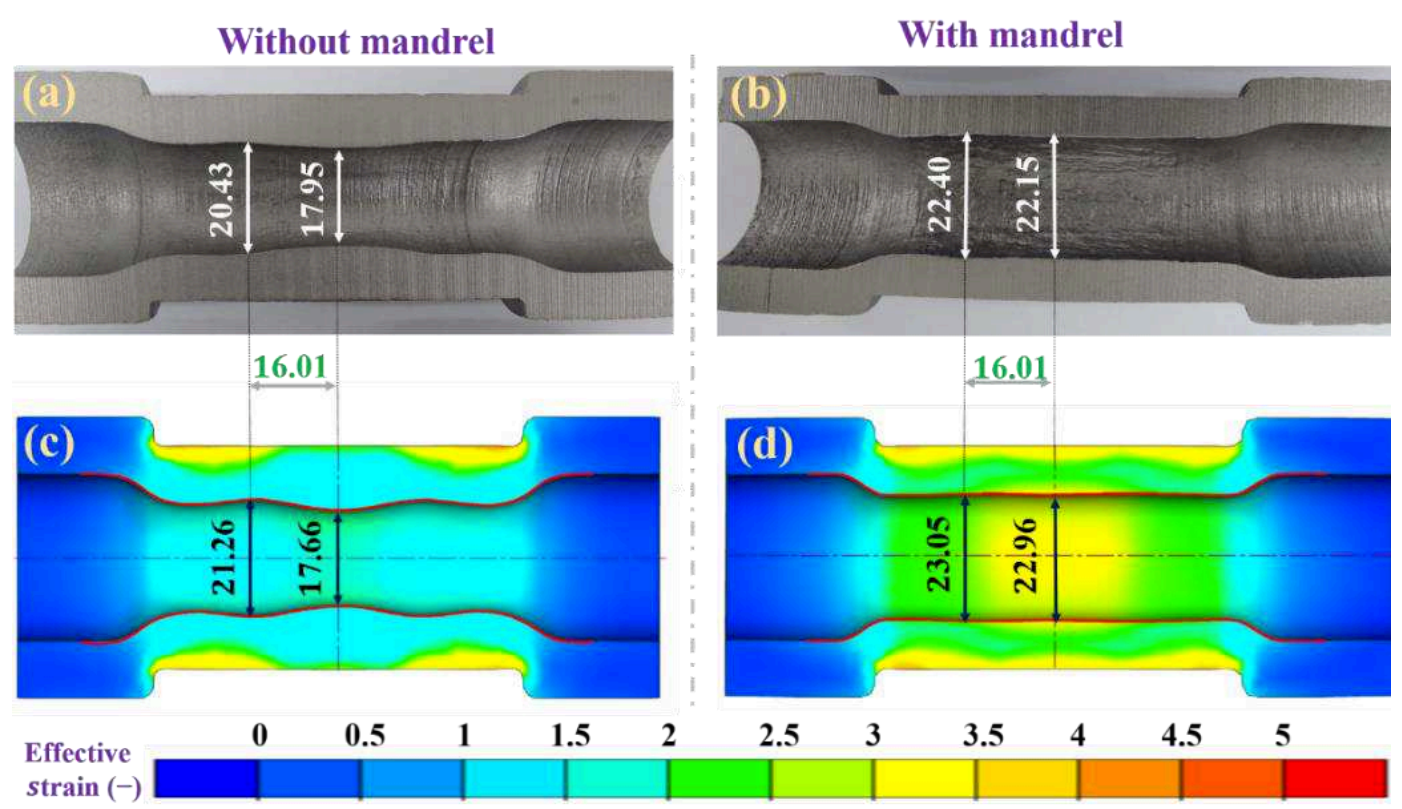

Fig. 18 Geometry comparison between $(a, b)$ physical experiments and (c, d) numerical simulations

The shape of rolled shafts of experimental tests have a good agreement with FE results. In the rolling process without mandrel, both physical and FE shafts have a defect of hole shrinkage on knifing position. But under the circumstance of having a mandrel, this defect is improved and both physical and FE shafts have a uniformed inner diameter.

The maximum and minimum diameters of inner holes are used for quantitative verification. The minimum inner hole diameter of FCWR without mandrel appears on

459 the knifing position with a value equal to $17.95 \mathrm{~mm}$ of physical shaft and $17.66 \mathrm{~mm}$ of 460 FE result, and its maximum hole diameter is equal to $20.43 \mathrm{~mm}$ in physical test and 
$21.26 \mathrm{~mm}$ in FE result. The maximum relative deviation (relative to physical result) of

462 four comparative diameters is $4 \%$ which lower than $10 \%$, so the FE results are reliable.

\subsubsection{Advantages and disadvantages}

Beside the validation experiments, some deformation tests were carried out with varied values of hole diameters. Simultaneously, the mandrel diameters were changed accordingly as $d m / d_{0}=0.73$. The other process parameters stayed the same as $D_{0}=50$ $\mathrm{mm}, \alpha=45^{\circ}, \beta=2^{\circ}, h=6 \mathrm{~mm}, B=18 \mathrm{~mm}$ and $T=1050^{\circ} \mathrm{C}$. The rolled shafts are presented in Fig. 19.

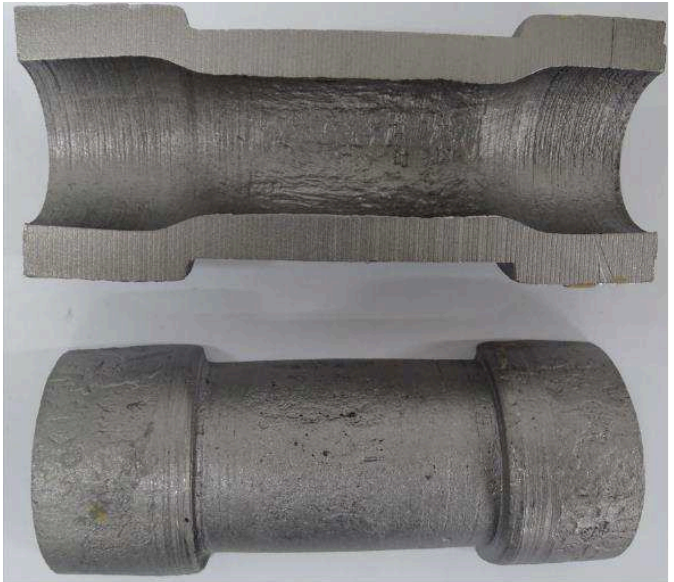

(a) $d_{0}=30 \mathrm{~mm}$

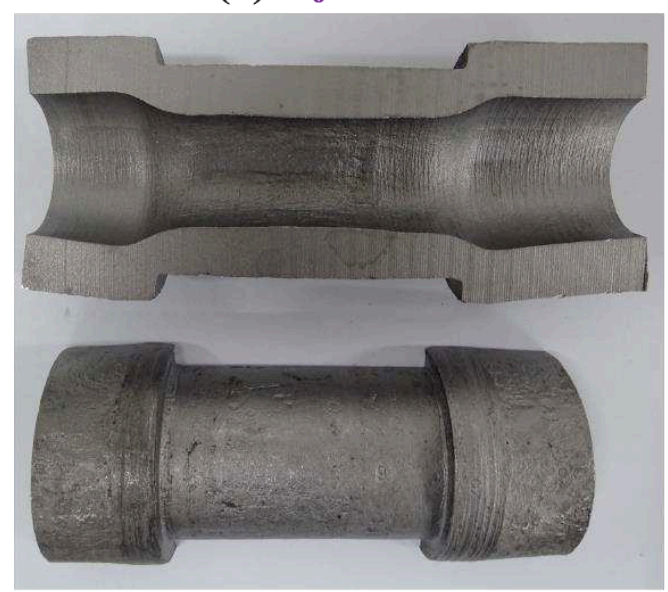

(c) $d_{0}=26 \mathrm{~mm}$

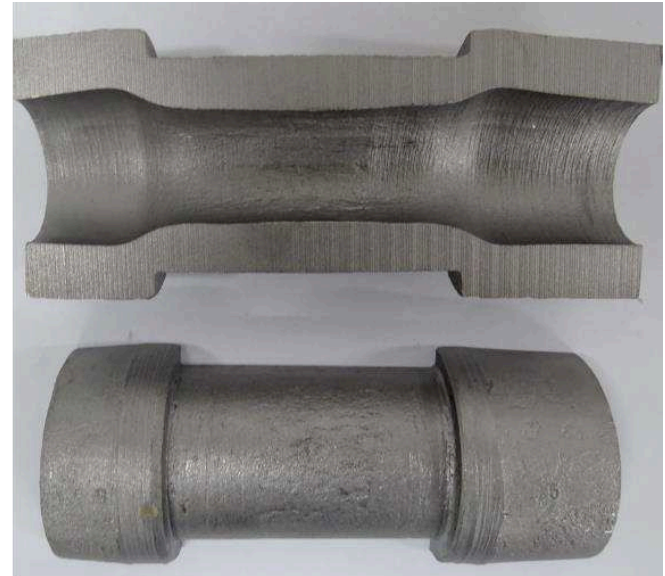

(b) $d_{0}=28 \mathrm{~mm}$

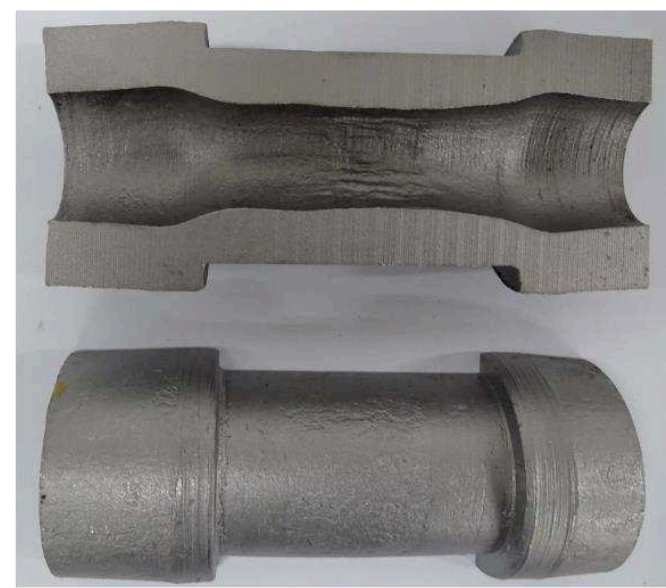

(d) $d_{0}=24 \mathrm{~mm}$

Fig. 19 Hollow shafts formed by FCWR with single guide in the horizontal multifunctional mill

By observing the geometric appearances, we can find that all the rolled pieces are

472 free from knifing groove and hole expansion. Therefore, a conclusion can be gained 
hole expansion.

Moreover, these hollow shafts have a good forming accuracy. For example, the right-angle steps are precisely rolled and the typical limitations are absent, such as sprial-grooved surface $[15,18]$, ellipse of formed shafts $[19,20]$. These experimental performances indicate that single guide rolling can improve rolling stability.

The grain size of rolled part is one of the most significant indicators, which decides the mechanical properties of the hollow products. The microstructure morphology of the rolled shaft is obtained in a microscope with 200 times magnification. As Fig. 20 shows, the grain sizes of the rolled regions $(\mathrm{P} 1, \mathrm{P} 2)$ are significantly smaller than that of unrolled region (P3), which can be explained that the grains are refined under FCWR deformation. Besides, the grain size at the knifing position (P1) is smaller than that at the stretching position (P2), which is consistent with the distribution of strain shown in Fig.18d, and can be considered that the knifing zone has a larger deformation than the stretching zone.

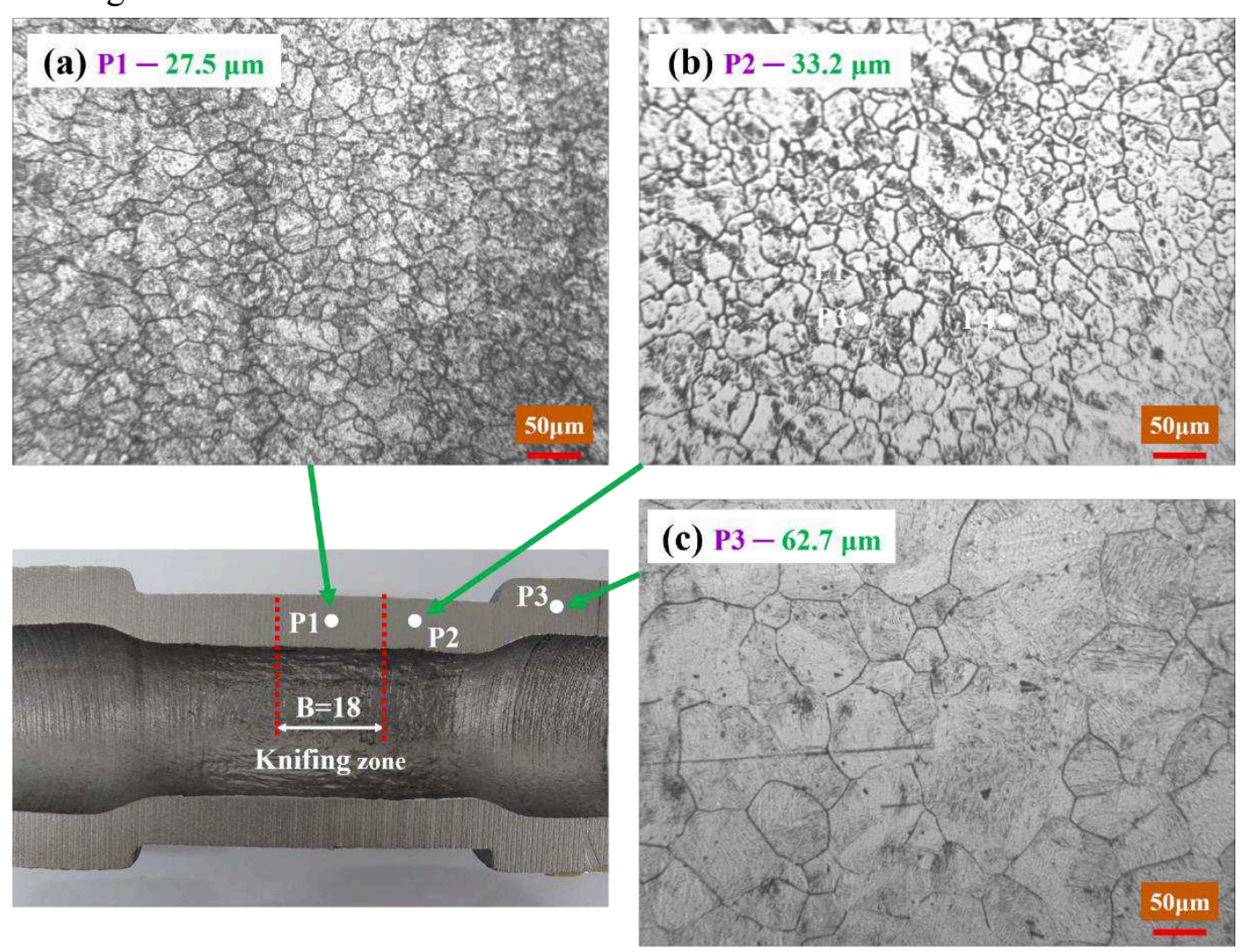

Fig. 20 Grain size of the FCWR rolled shaft at different locations 
as well. As arisen in the numerical simulations and physical experiments, the rolled 491 shaft cannot be automatically ejected from the mill so a new discharging device is needed. Besides, FCWR process deteriorates the ellipse of hole and increases rolling

493 force and rotating torque.

\subsubsection{Application to the solid shafts}

For solid shafts, the FCWR advantage of avoiding hole expansion is no longer necessary. However, it also takes advantages of avoiding knifing groove and reducing the perimeter of rollers.

The major considerations for solid shafts rolling are whether billet can rotate normally and whether central cracks can be avoided. On the one hand, because an BB section (shown in Fig. 10b) is added at the knifing zone, the friction conditions at knifing stage are improved theoretically owing to the contacting area increases. On the other hand, the trend of central cracking is relieved because the added radial compression-force is beneficial to metal bonding. And when it comes to stretching and sizing stage, the deformation of NCWR and FCWR is the same. Therefore, it can be estimated that this novel FCWR process can be used for solid shafts under the condition of reasonable knifing width.

\section{Summary and conclusions}

In this paper, a novel process of flat-knifing cross-wedge rolling (FCWR) with single guide was proposed to manufacture hollow shafts, including a CWR roller, single guide rolling and a horizontal multifunctional mill. The following conclusions are obtained:

(1) The defects of hole expansion and knifing groove are absolutely avoided because FCWR roller produces a radial force to shrink the hole and avoids the deformation concentration of outer surface during knifing stage;

(2) The new type of horizontal multifunctional mill can be used to perform laboratory tests such as longitudinal rolling, cross rolling and helical rolling and 
517 expected to have industrial application as thread rolling mill, ball rolling mill and cross-

518 wedge rolling mill;

519 (3) The single guide rolling can be realized by workpiece axis offset from the 520 center line of two rollers, and can improves the rolling stability and simplifies the mill 521 structure;

522 (4) The flat-knifing roller reduce the wedge length in the range of 200 800 mm;

523 (5) The process of flat-knifing cross-wedge rolling with single guide brings the 524 shortcomings of non-automatic ejecting, hole ellipse and increasement of rolling force 525 and rotating torque;

526 (6) The process of FCWR with single guide is estimated to form the solid shafts 527 under the condition that knifing width is designed reasonably.

\section{Compliance with Ethical Standards}

\section{Acknowledgments}

530 This work is supported by the National Key R\&D Program of China (Grant No. 531 2018YFB1307900). This work is funded by the National Natural Science Foundation 532 of China (Grant No. 51875036).

\section{Conflict of interest statement}

534 We declare that we have no financial and personal relationships with other people 535 or organizations that can inappropriately influence our work, there is no professional or 536 other personal interest of any nature or kind in any product, service and/or company 537 that could be construed as influencing the position presented in, or the review of, the 538 manuscript entitled.

\section{Ethical approval}

540 This article does not contain any studies with human participants or animals 541 performed by any of the authors.

\section{Informed consent}

543 All the authors listed have approved the manuscript that is enclosed.

\section{Authors' contributions}


546 Wang: Project administration, Supervision, Funding acquisition. Jinxia Shen:

547 Methodology, Writing-Reviewing \& Editing. Tao Liu: Investigation, Data Curation,

$548 \quad$ Writing-Reviewing \& Editing.

549 Availability of data and materials

550 The datasets generated and/or analysed during the current study are available from

551 the corresponding author on reasonable request.

\section{Consent to participate}

553 Applicable.

\section{Consent to publish}

$555 \quad$ Applicable.

556

557

558

559

560

561

562

563

564

565

566

567

568

569

570

571

572

573

574

575

576

\section{References}

[1] Romanenko V, Stepanov P, Kriskovich S (2018) Production of hollow railroad axles by screw piercing and radial forging. Metallurgist. 61:873-877. https://doi.org/10.1007/s11015-018-0579-0

[2] Ji H, Liu J, Wang B, et al (2017) A new method for manufacturing hollow valves via cross wedge rolling and forging: Numerical analysis and experiment validation. J. Mater. Process. Technol. 240:1-11. https://doi.org/10.1016/j.jmatprotec.2016.09.004

[3] Yang C, Ma J, Hu Z (2017) Analysis and design of cross wedge rolling hollow axle sleeve with mandrel. J. Mater. Process. Technol 239:346-358. https://doi.org/10.1016/j.jmatprotec.2016.09.002

[4] Hu, Z, Wang, B, Zheng Z (2018) Research and industrialization of near-net rolling technology used in shaft parts. Front. Mech. Eng 13:17-24. https://doi.org/10.1007/s11465-018-0480-3

[5] Pater Z, Tofil A (2017) Overview of the research on roll forging processes. Advances in Science and Technology Research Journal 11(2):72-86. https://doi.org/10.12913/22998624/70645

[6] Huo Y, Lin J, Bai Q, Wang B, Tang X, Ji H (2017) Prediction of microstructure and ductile damage of a high-speed railway axle steel during cross wedge rolling. J. Mater.

Process.

Technol

239:359-369. https://doi.org/10.1016/j.jmatprotec.2016.09.001 
[7] Pater Z, Tomczak J, et al (2021) Conception of a three roll cross rolling process of hollow rail axles. ISIJ International
https://doi.org/10.2355/isijinternational.ISIJINT-2020-530

580 [8] Peng W, Zheng S, Chiu Y, Shu X, Zhan L (2016) Multi-wedge cross wedge rolling process of $42 \mathrm{CrMo} 4$ large and long hollow shaft. Rare Metal Materials and Engineering 45(4): 836-842. https://doi.org/10.1016/S1875-5372(16)30084-4

[9] Bartnicki J, Pater Z (2004) The aspects of stability in cross-wedge rolling processes of hollowed shafts. J. Mater. Process. Technol 155-156:1867-1873. https://doi.org/10.1016/j.jmatprotec.2004.04.278

[10] Bartnicki J, Pater Z (2005) Numerical simulation of three-rolls cross-wedge rolling of hollowed shaft. J. Mater. Process. Technol 164-165:1154-1159. https://doi.org/10.1016/j.jmatprotec.2005.02.120

[11]Urankar S, Lovell M, Morrow C, Li Q, Kawada K (2006) Establishment of failure conditions for the cross-wedge rolling of hollow shafts. J. Mater. Process. Technol 177:545-549. https://doi.org/10.1016/j.jmatprotec.2006.04.052

[12] Neugebauer R, Glass R, Kolbe M (2002) Optimisation of processing routes for cross rolling and spin extrusion. J. Mater. Process. Technol 125:856-862. https://doi.org/10.1016/S0924-0136(02)00392-8

[13]Landgrebe D, Steger J, Böhmichen U, et al (2018) Modified cross-wedge rolling for creating hollow shafts. Procedia Manufacturing 21:53-59. https://doi.org/10.1016/j.promfg.2018.02.094

[14] Shen J, Wang B, Lin L, Li J, Zhu C (2020) Investigation on the hole evolution and forming dimensions during cross wedge rolling hollow shaft with mandrel. Procedia Manufacturing

50:143-147. https://doi.org/10.1016/j.promfg.2020.08.027

[15] Shen J, Wang B, Zhou J, Huang X, Li J (2019) Numerical and experimental research on cross wedge rolling hollow shafts with a variable inner diameter. Arch Civ Mech Eng 4:1497-1510. https://doi.org/10.1016/j.acme.2019.08.003

[16] Shen J, Wang B, et al (2021) Theoretical study and prediction of the inner hole reduction and critical mandrel diameter in cross wedge rolling of hollow shaft. J. Mater. Process. Technol 294(2):117140. https://doi.org/10.1016/j.jmatprotec.2021.117140

[17]Ji H, Liu J, Wang B, et al (2016) Constitutive relationship of 4Cr9Si2 and technological parameters on the inner bore of cross wedge rolling for preform hollow valves. Int. J. Adv. Manuf. Tech 86(9-12):1-13. https://doi.org/10.1007/s00170-016-8360-7

[18] Shu X, Shi J, Chen Ji, Yang H (2021) Effect of process parameters on surface 
quality of shafts parts formed by warm cross wedge rolling. Int. J. Adv. Manuf. Tech 113:2819-2813. https://doi.org/10.1007/s00170-021-06784-2

[19]Huang X, Wang B, et al (2019) Investigation on the effect of mandrels on hollow shafts in cross-wedge rolling. Int. J. Adv. Manuf. Tech 102:443-455. https://doi.org/10.1007/s00170-018-3093-4

[20]Feng P, Yang C, Wang B, et al (2021) Formability and microstructure of TC4 titanium alloy hollow shafts formed by cross-wedge rolling with a mandrel. Int. J. Adv. Manuf. Tech 114:365-377. https://doi.org/10.1007/s00170-021-06635-0

[21]Pater Z. Cross-Wedge Rolling (2014) Comprehensive Materials Processing, Button, S.T, Ed. Elsevier Ltd 3:211-279. https://doi.org/10.1016/B978-0-08-096532$1.00315-0$

[22] Shu X, Shchukin V, Kozhevnikova G, et al (2004) Theory and technology of cross wedge rolling. Beijing: The Science Publishing Company. ISBN: 978-7-03040397-1 (In Chinese).

[23] Wang B, Lin L, Wang S, Yang C, Liu S, Zhang H (2020) Flexible skew rolling mill with dual-rotatable-shafts. United State Patent. No, 20200398323.

[24]Huang X, Wang B, et al (2017) Effect of mandrel diameter on non-circularity of hollow shafts in cross wedge rolling. Procedia Eng 207:2376-2381. https://doi.org/10.1016/j.proeng.2017.10.1011

[25]Tofil A, Tomczak J, Bulzak T (2015) Numerical and experimental study on producing aluminium alloy 6061 shafts by cross wedge rolling using a universal rolling mill. Arch. Metall. Mater 60(2):801-807. https://doi.org/10.1515/amm$\underline{2015-0210}$

[26]Pater Z, Tomczak J, Bulzak T (2016) Cross-wedge rolling of driving shaft from titanium alloy Ti6Al4V Key Eng Mat 687:125-32. https://doi.org/10.4028/www.scientific.net/KEM.687.125

[27]Lis K, Wójcik U, Pater Z (2016) Numerical analysis of a skew rolling process for producing a crankshaft preform. Open Engineering 6:581-584. https://doi.org/10.1515/eng-2016-0087

[28] Pater Z, Tomczak J, Lis K, et al (2020) Forming of rail car axles in a CNC skew rolling mill. Arch Civ Mech Eng 20:69-82. https://doi.org/10.1007/s43452-020$\underline{00075-5}$ 
Figures

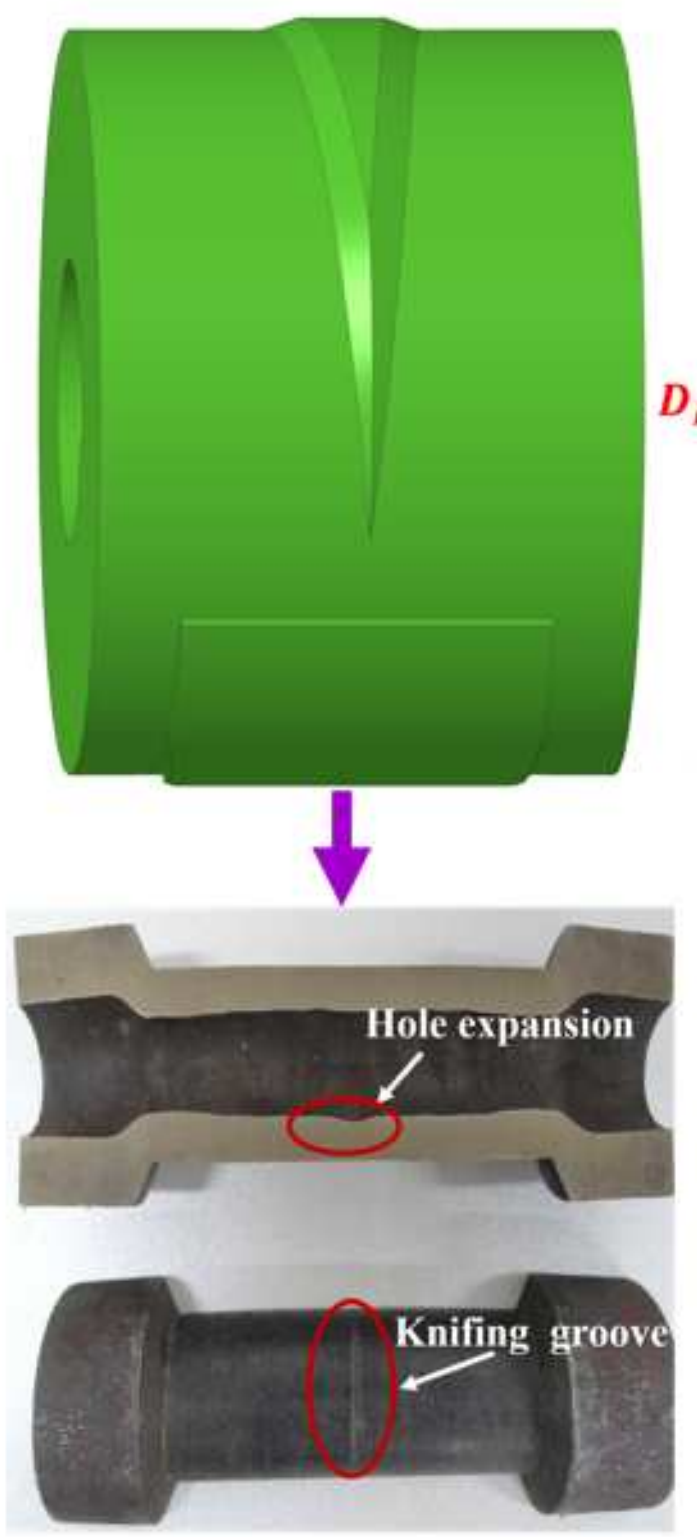

(a)

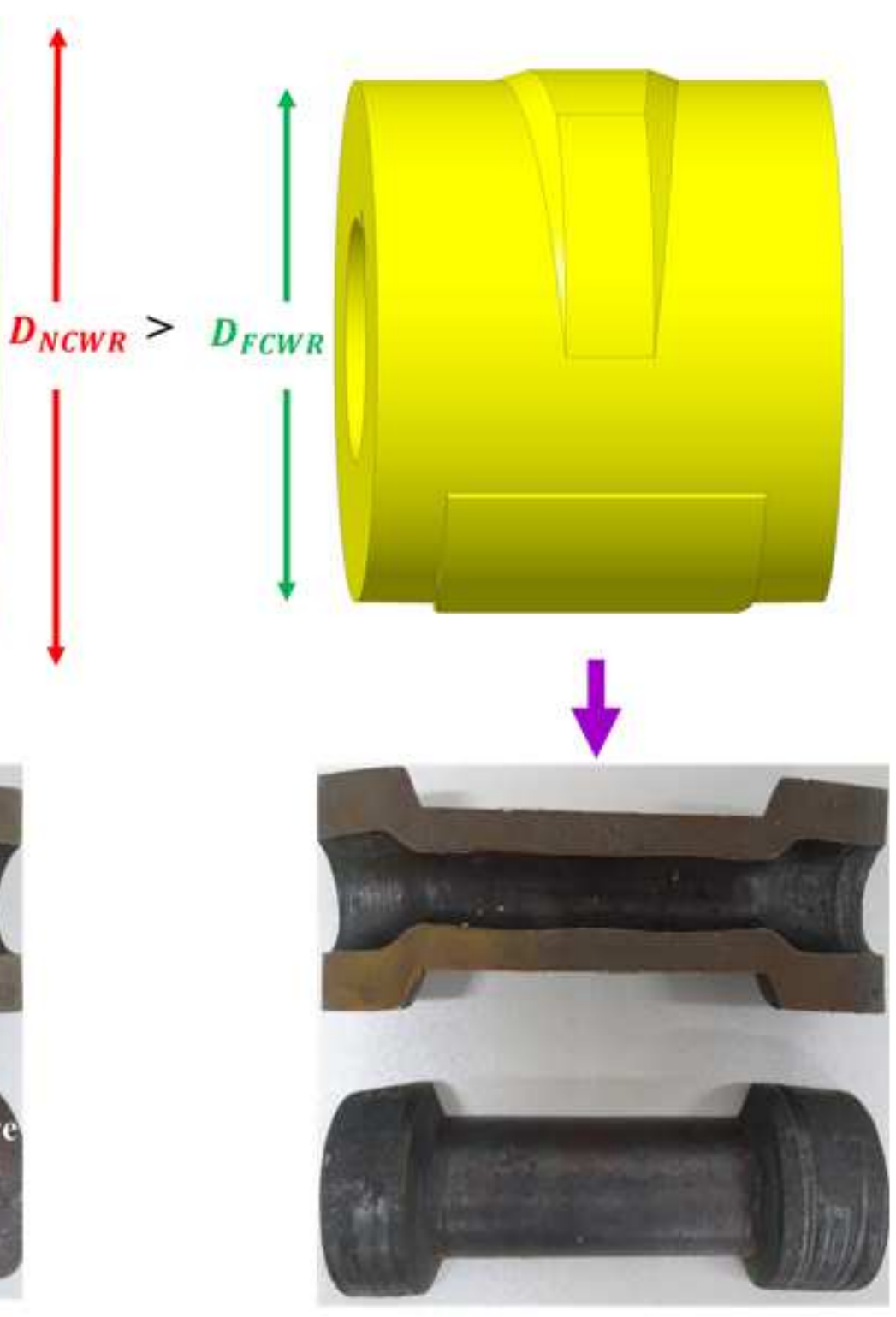

(b)

\section{Figure 1}

Contrast between two methods for hollow shafts $\mathbb{(}(\mathrm{a})$ normalized CWR; (b) flat-knifing CWR 

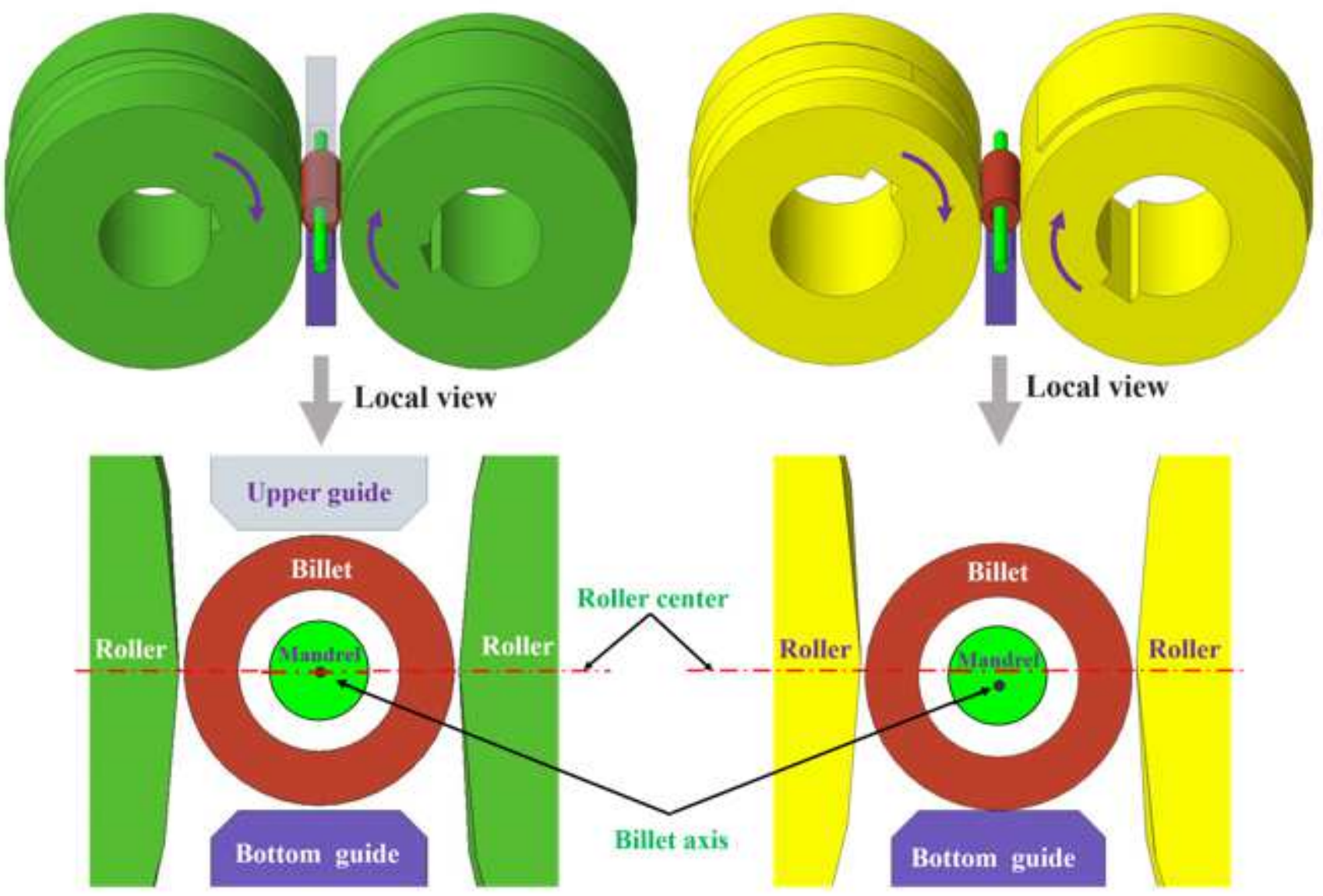

(a)

(b)

Figure 2

Process principle: (a) NCWR with two guides; (b) FCWR with single guide 


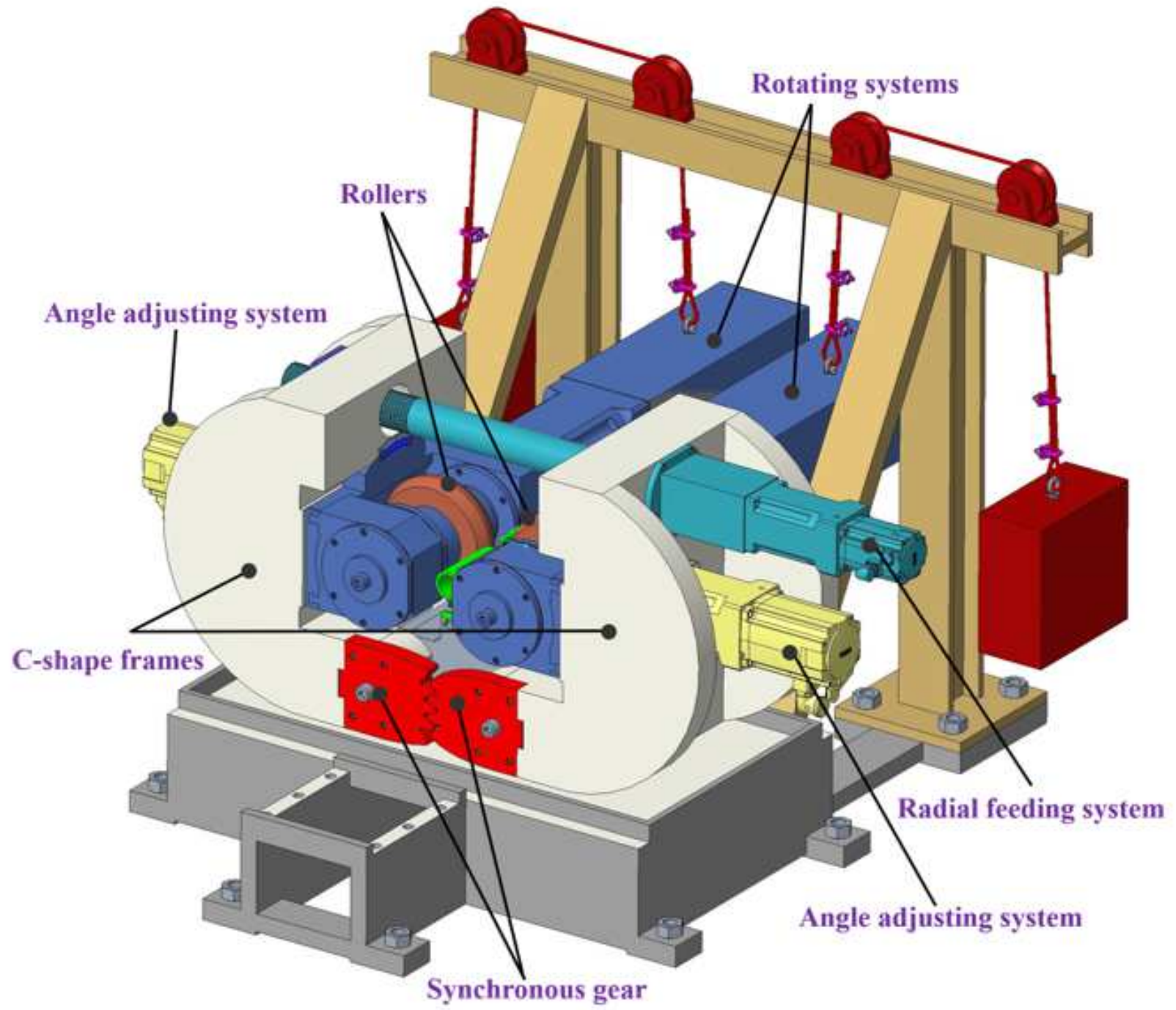

Figure 3

Geometrical model of the horizontal multifunctional mill 


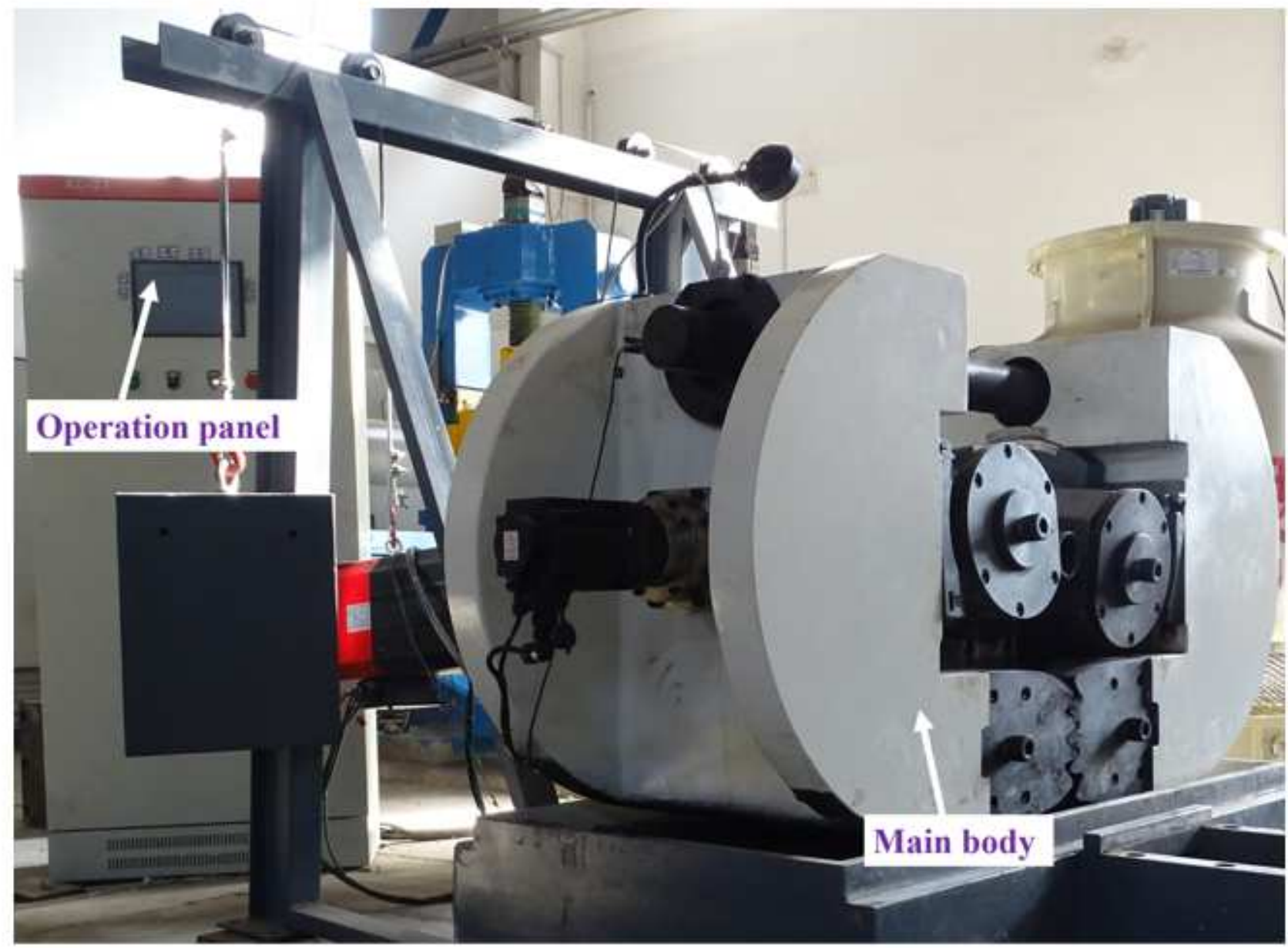

Figure 4

The constructed horizontal multifunctional mill 


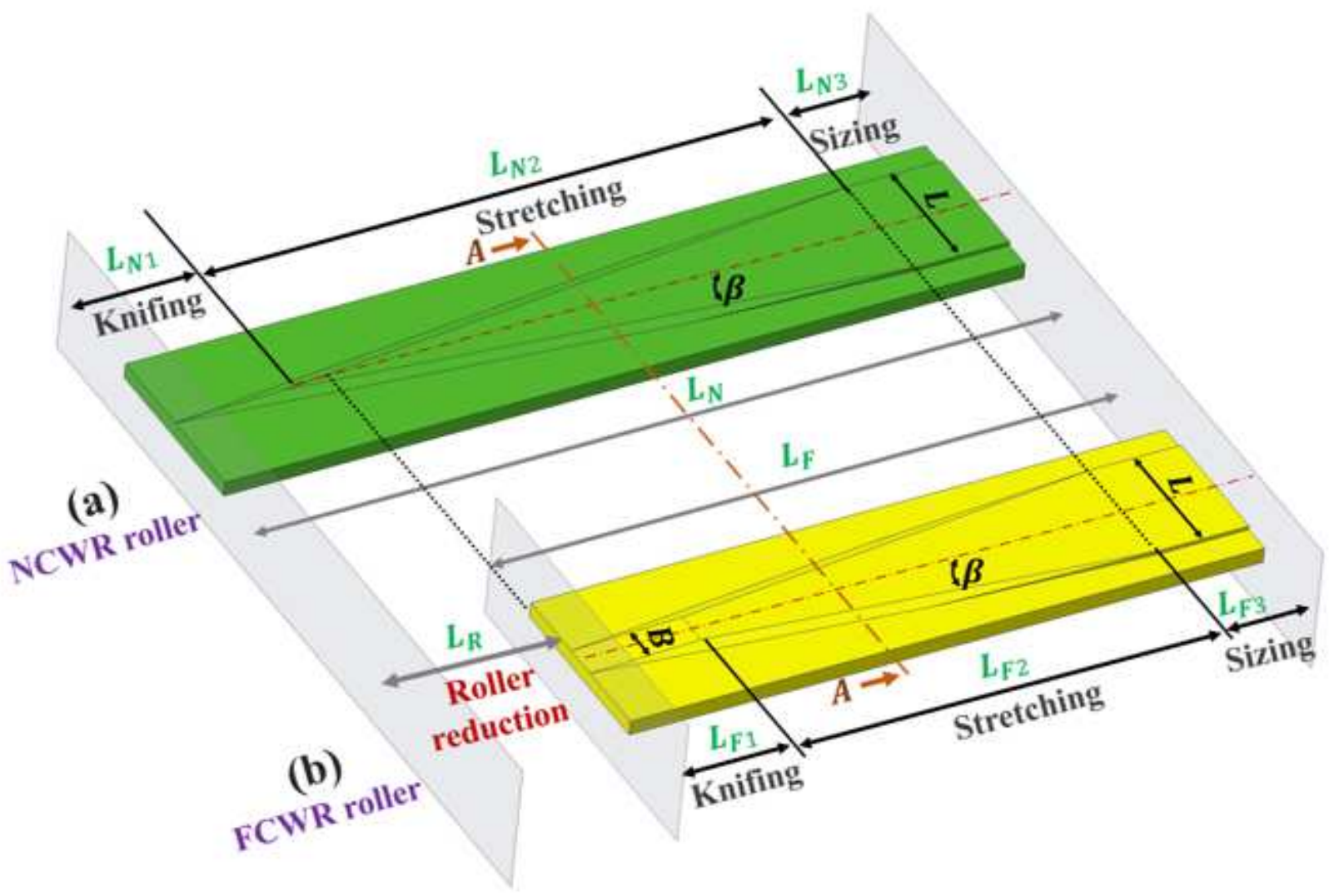

Figure 5

Configuration and major parameters of NCWR and FCWR roller 


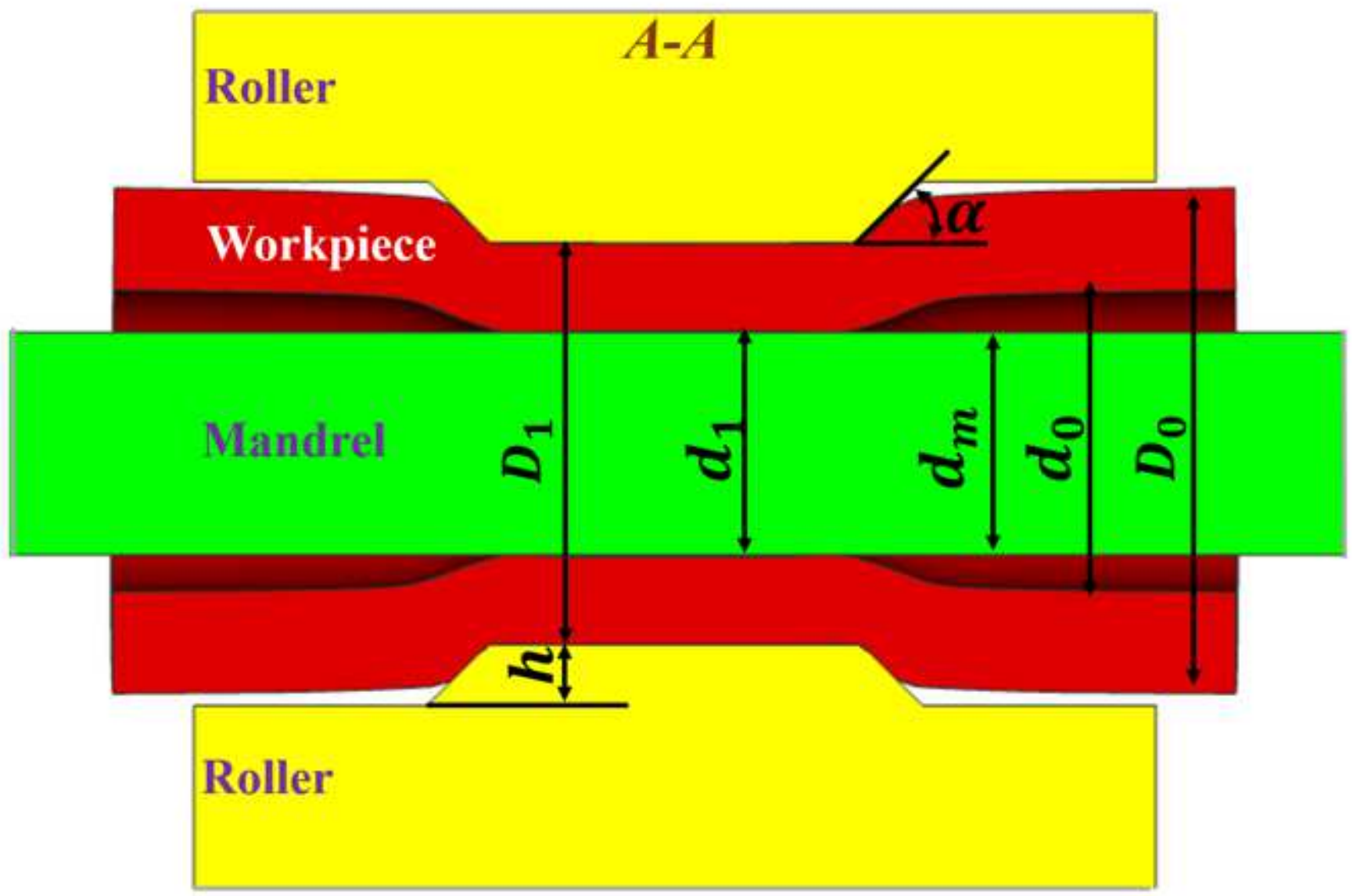

Figure 6

Contact model of roller, mandrel and workpiece at the stretching stage

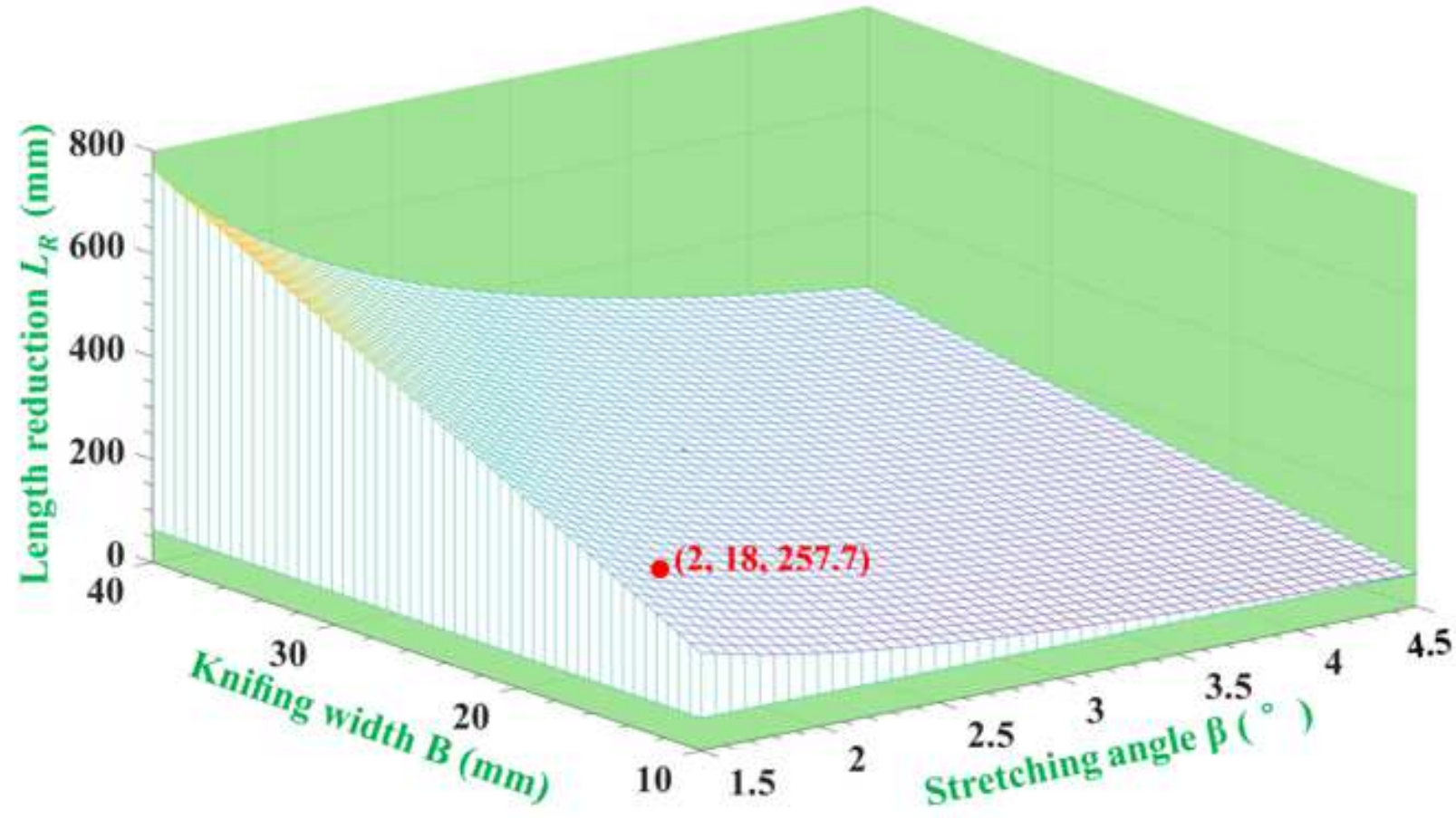


Figure 7

Relationship between wedge-length reduction and process parameters

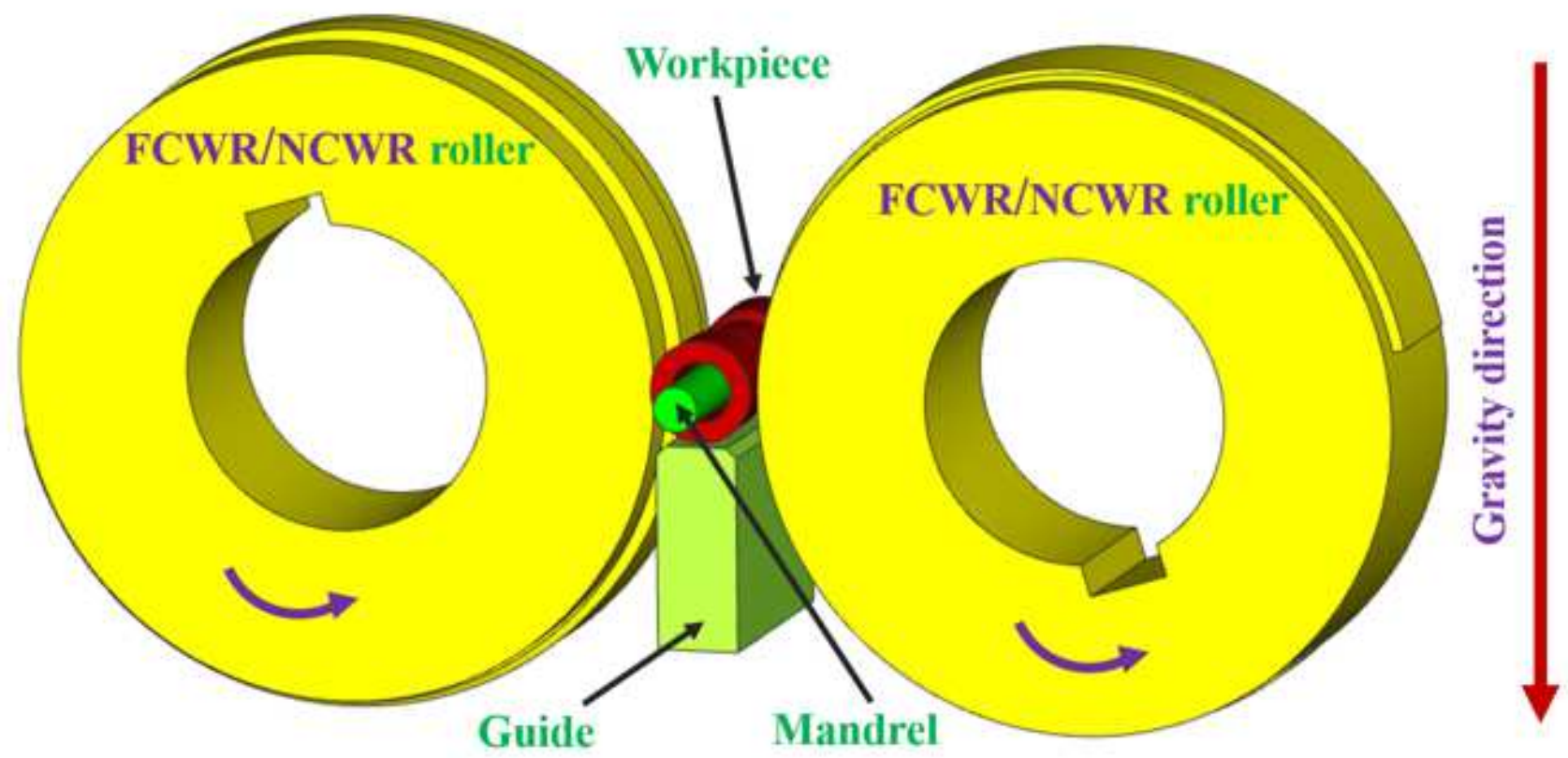

Figure 8

FE projects of FCWR and NCWR with single guide 


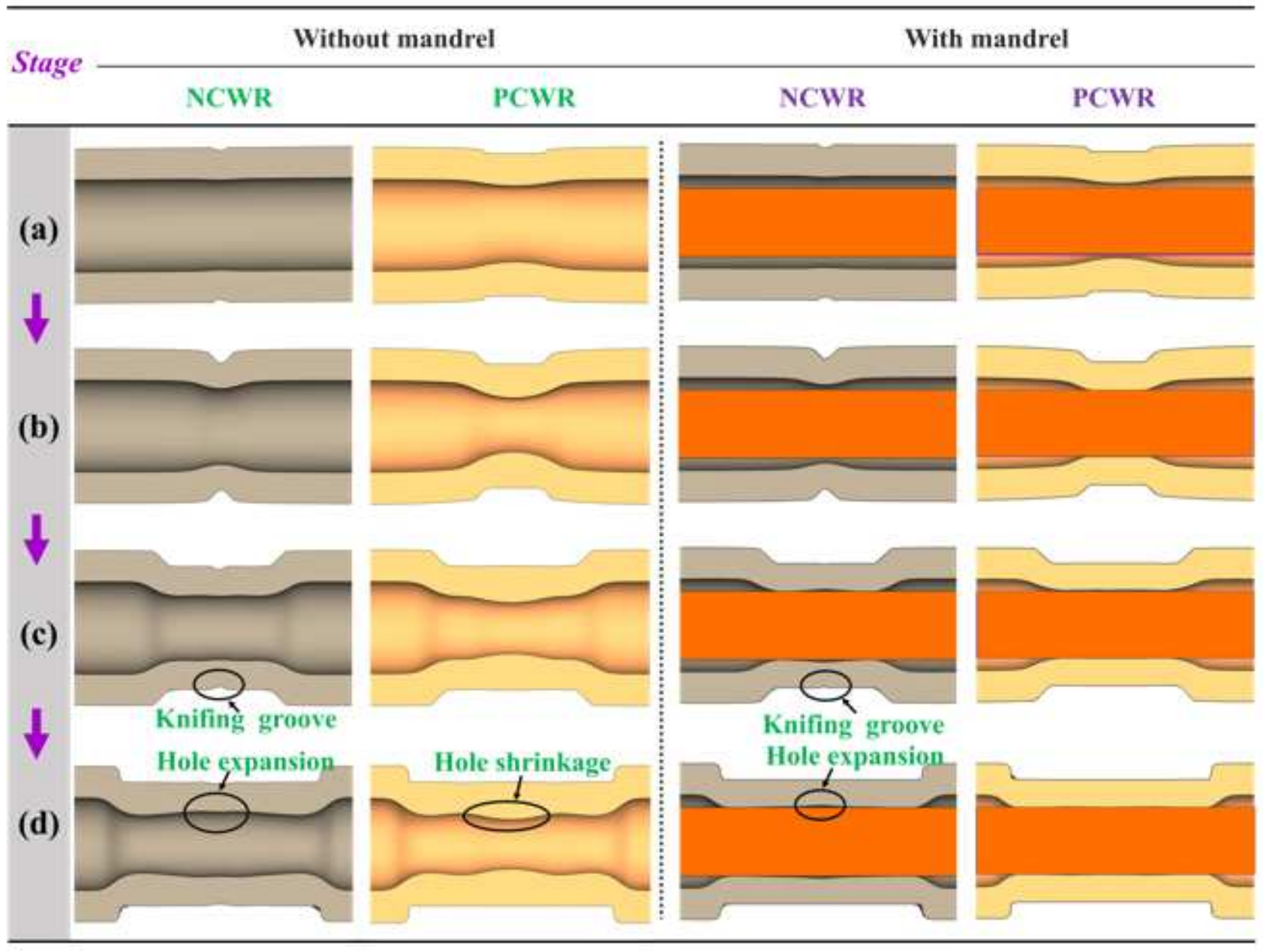

\section{Figure 9}

FE results of NCWR and FCWR: (a) middle of knifing stage; (b) end of knifing stage; (c) middle of stretching stage; (d) end of stretching stage 


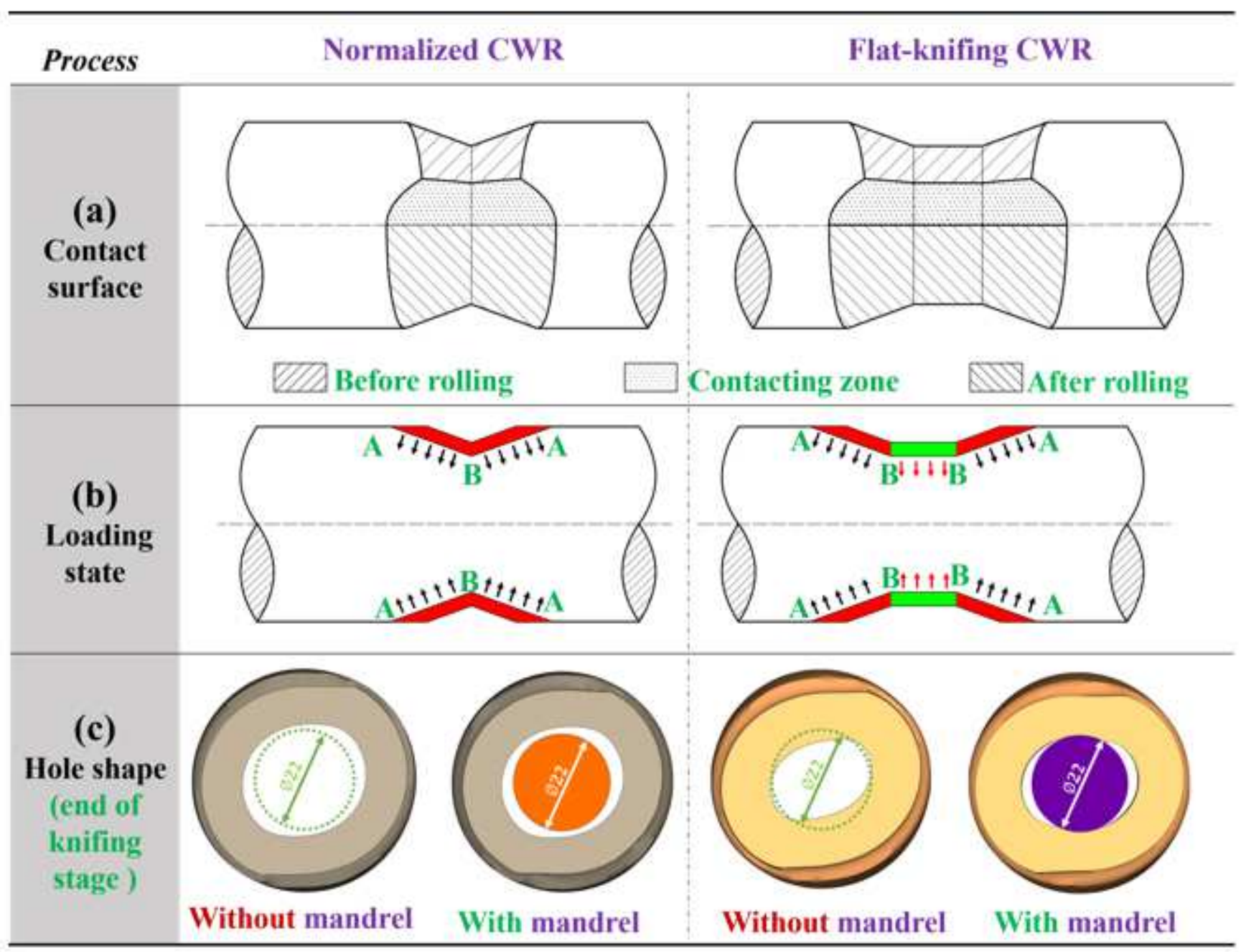

Figure 10

Formation mechanism of hole expansion (end of knifing stage): (a) contact surface; (b) loading states; (c) hole shape 
(a)

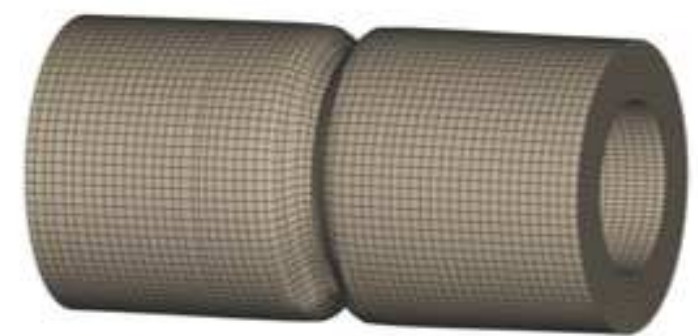

(b)

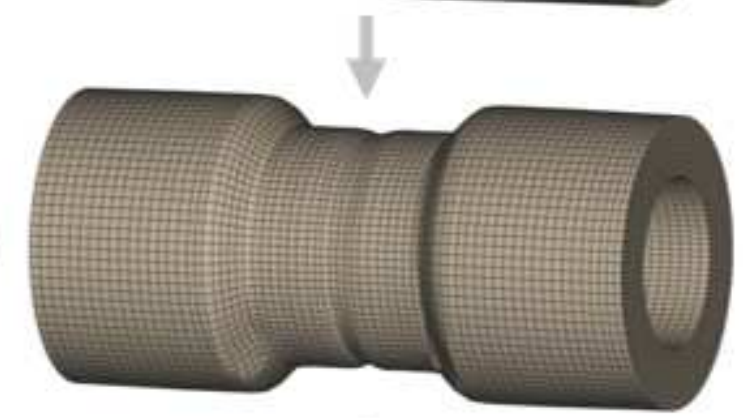

(c)

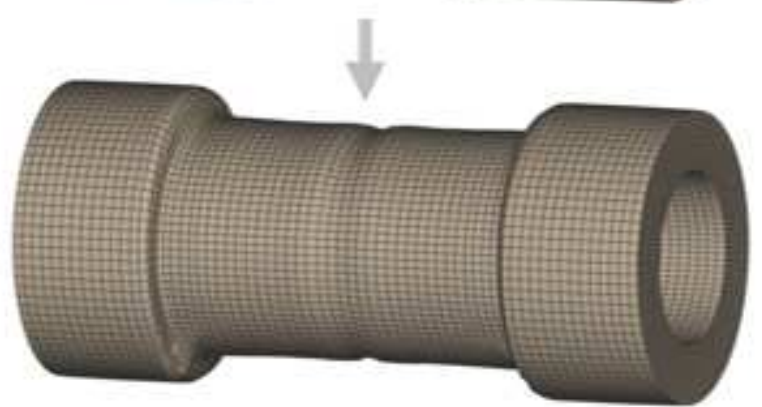

NCWR without mandrel
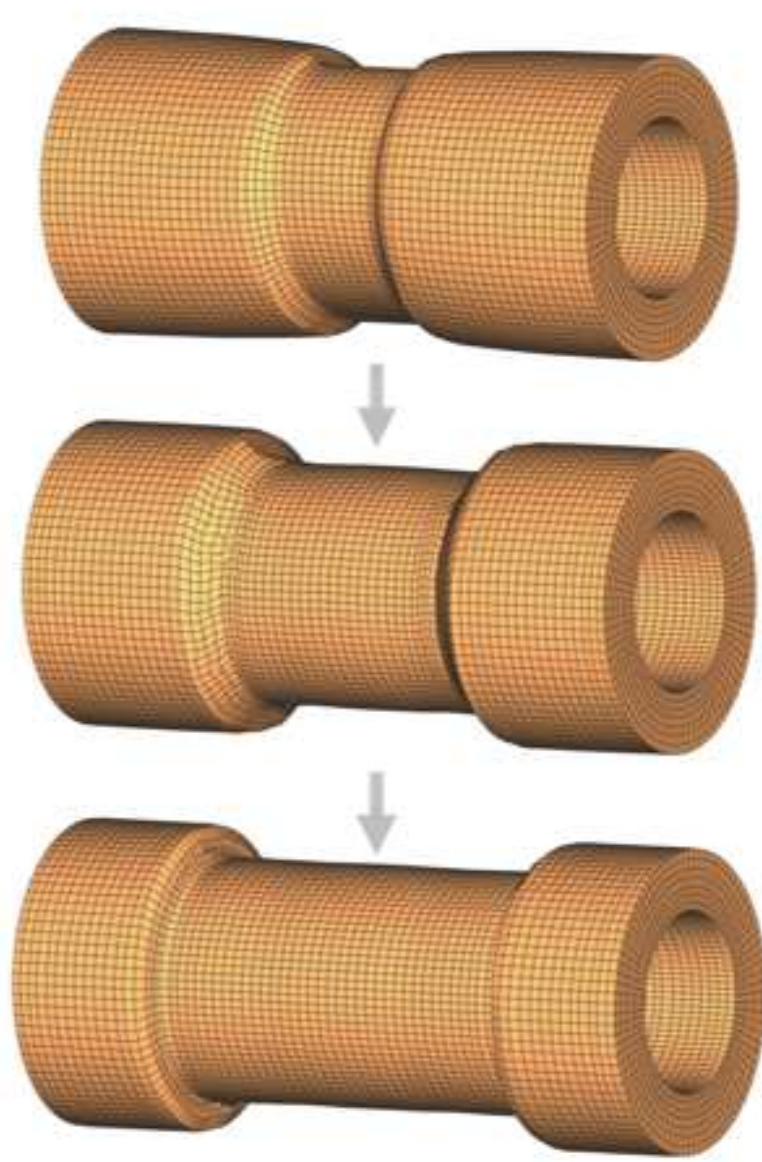

FCWR without mandrel

\section{Figure 11}

Geometry comparison between NCWR and FCWR workpiece: (a) end of knifing stage; (b) middle of stretching stage; (c) end of stretching stage

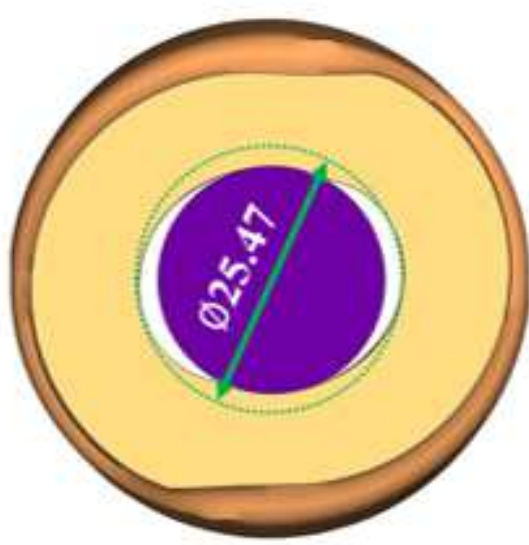

(a) $B=14 \mathrm{~mm}$

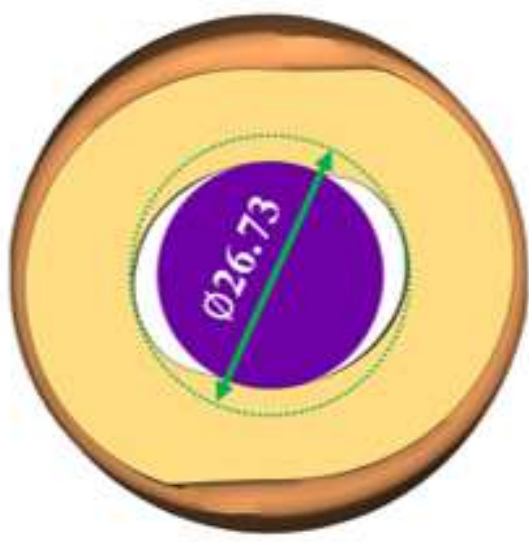

(b) $B=18 \mathrm{~mm}$

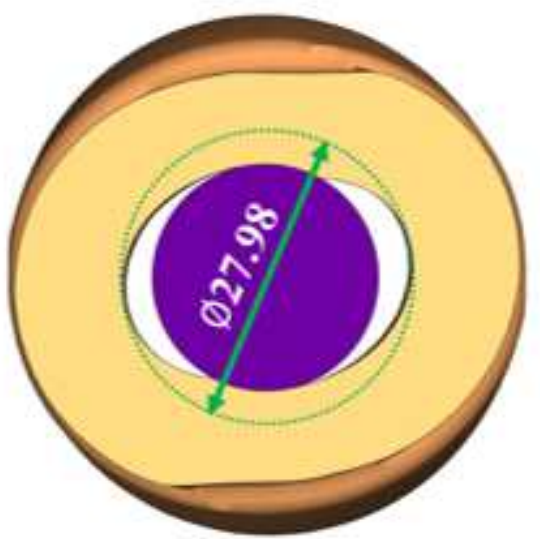

(c) $B=22 \mathrm{~mm}$ 
Relationship between knifing width and hole ovality (end of knifing stage)
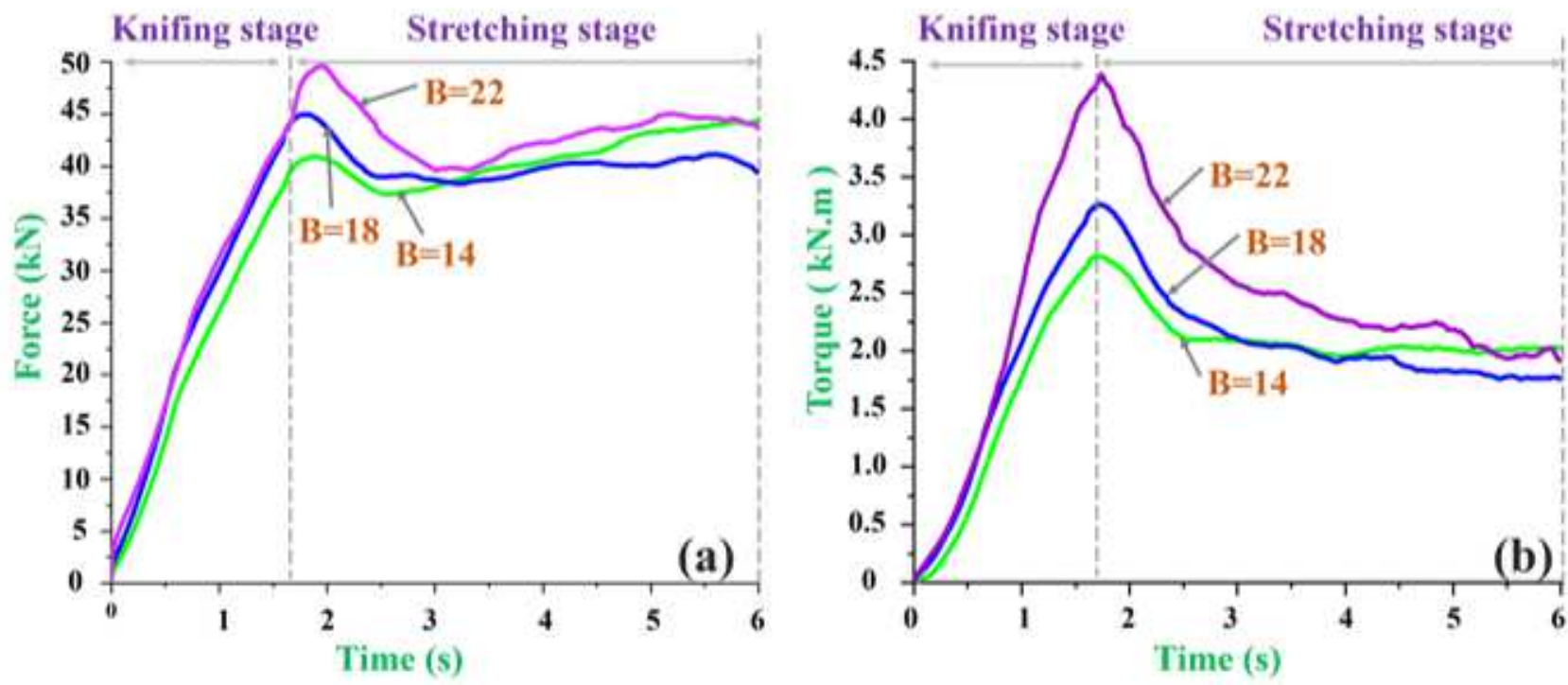

Figure 13

Relationship between knifing width, (a) rolling force, (b) rotating torque

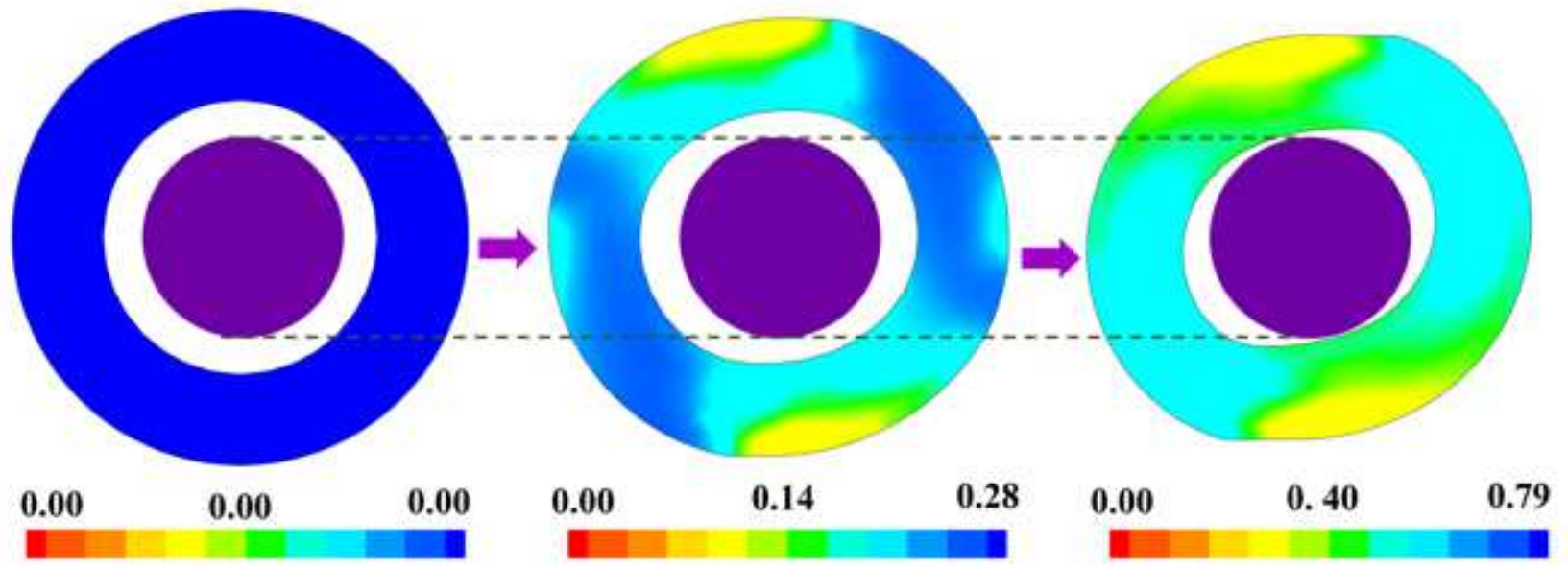

(a)

(b)

(c)

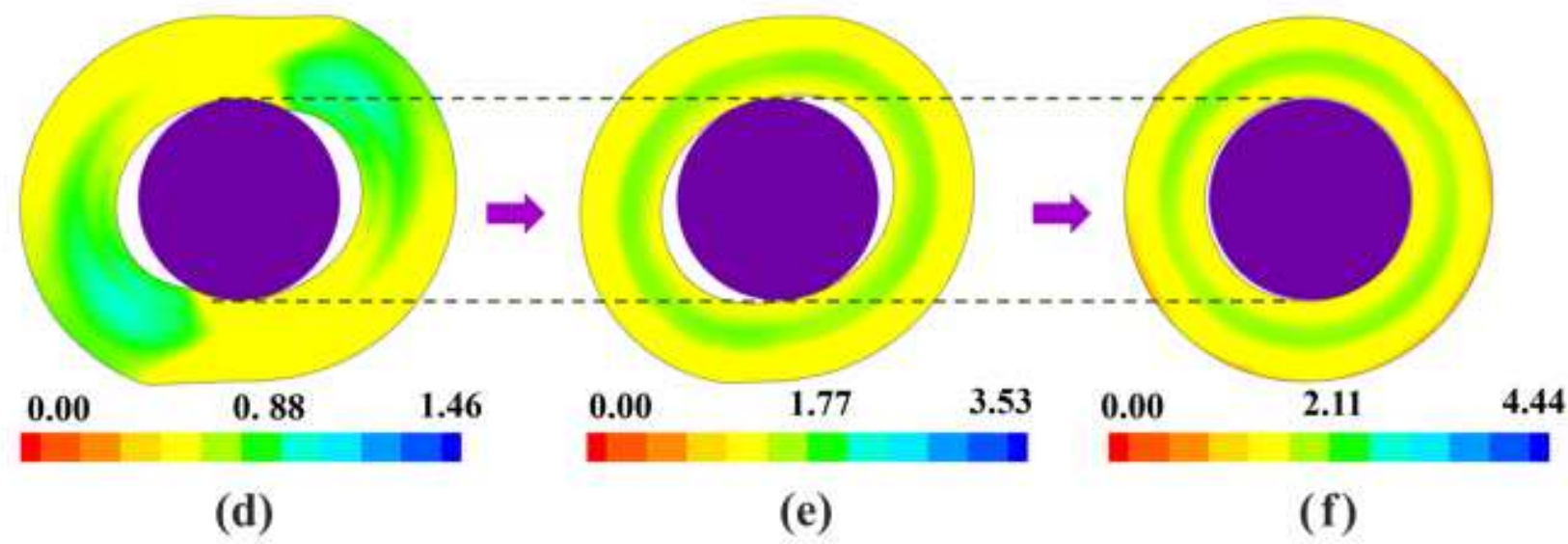

Figure 14 
Formation of the FCWR hole (with strain distribution): (a) initial status; (b) begin of workpiece flattening; (c) begin of mandrel contacting; (d) begin of hole sizing; (e) middle of hole sizing; (f) end of hole sizing

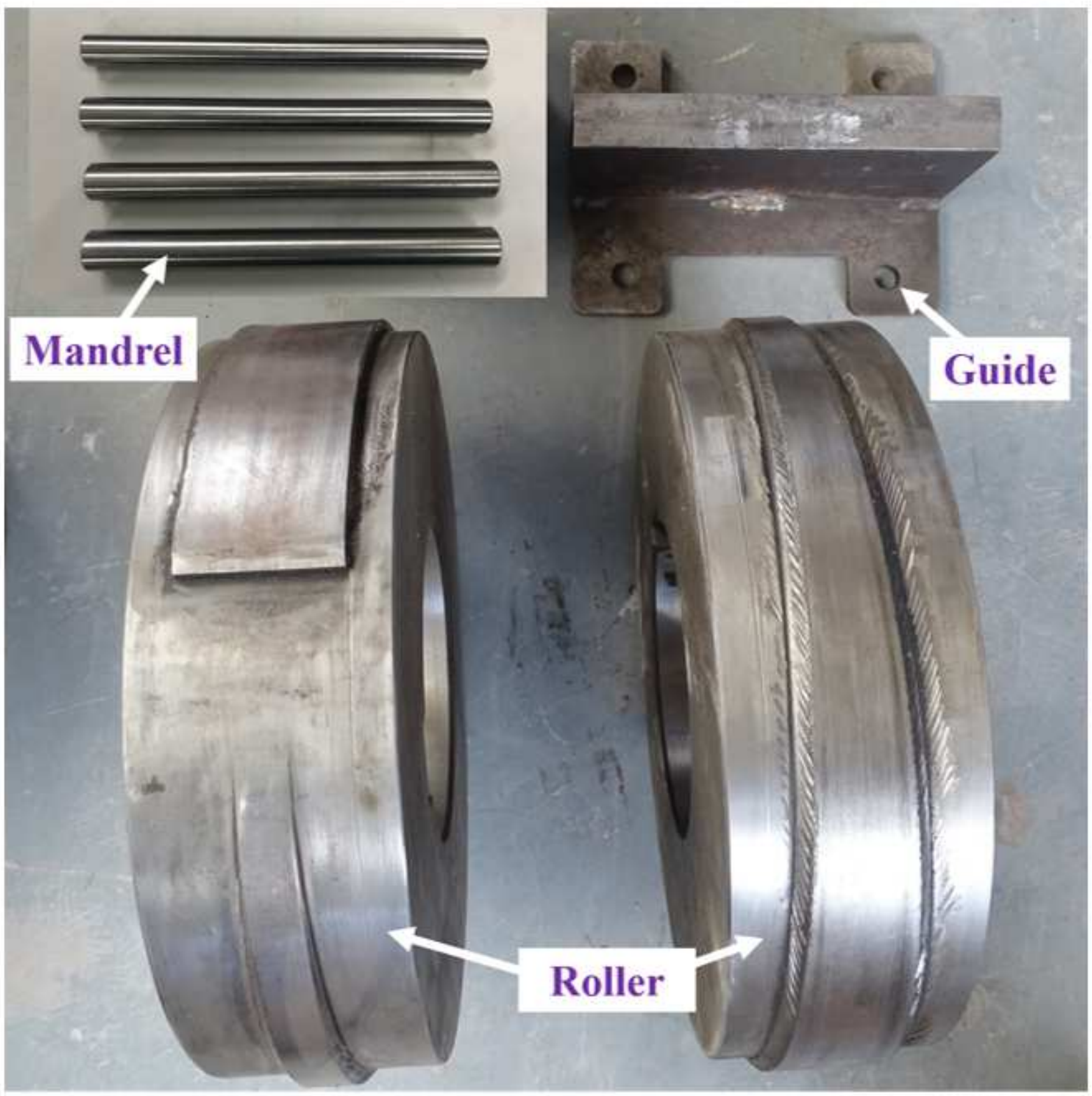

Figure 15

Tools for FCWR experiments with single guide for hollow shafts 

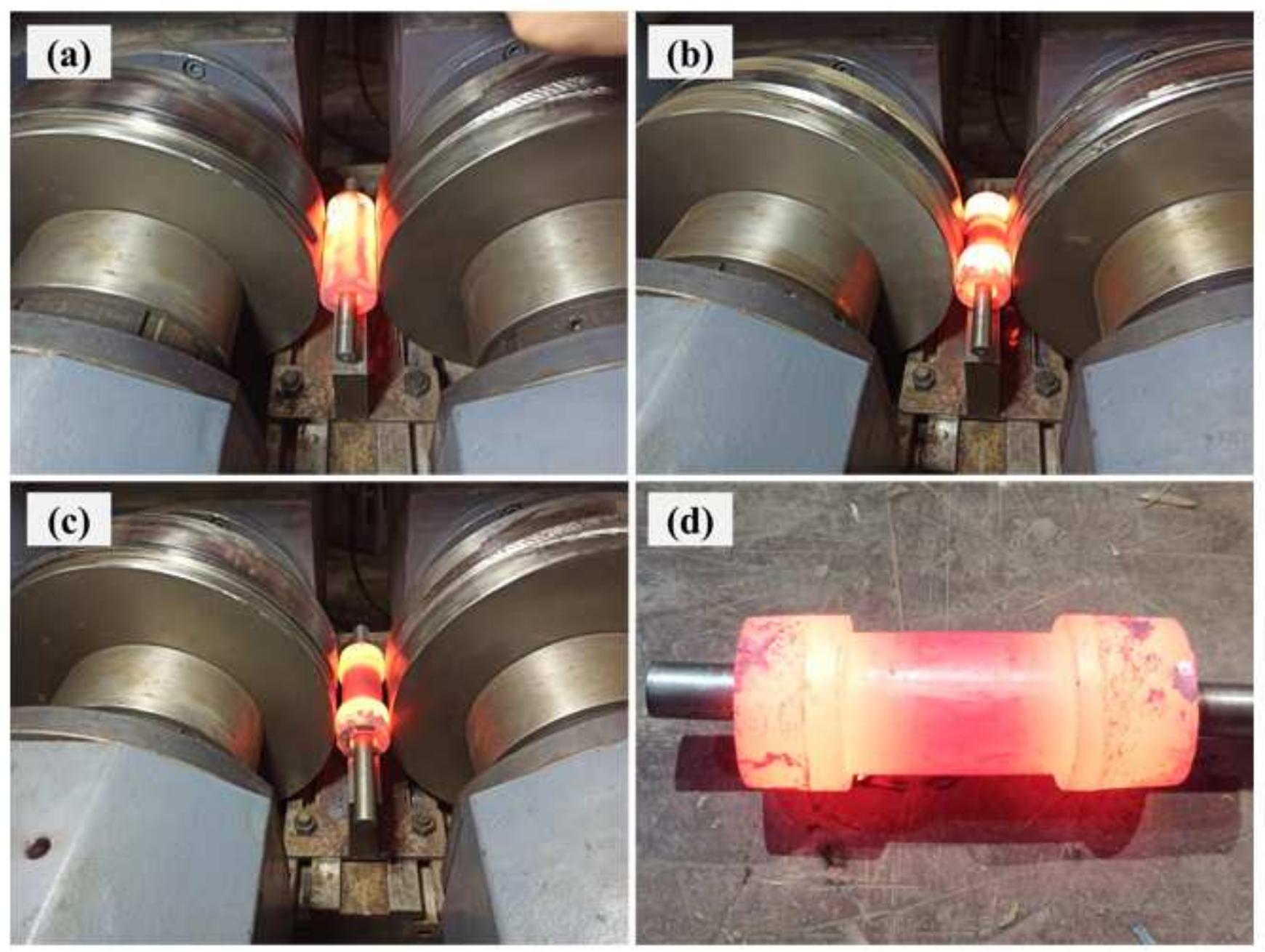

\section{Figure 16}

FCWR rolling experiments in horizontal multifunctional mill with single guide: (a) beginning; (b) rolling stage; (c) ending stage; (d) rolled hollow shaft
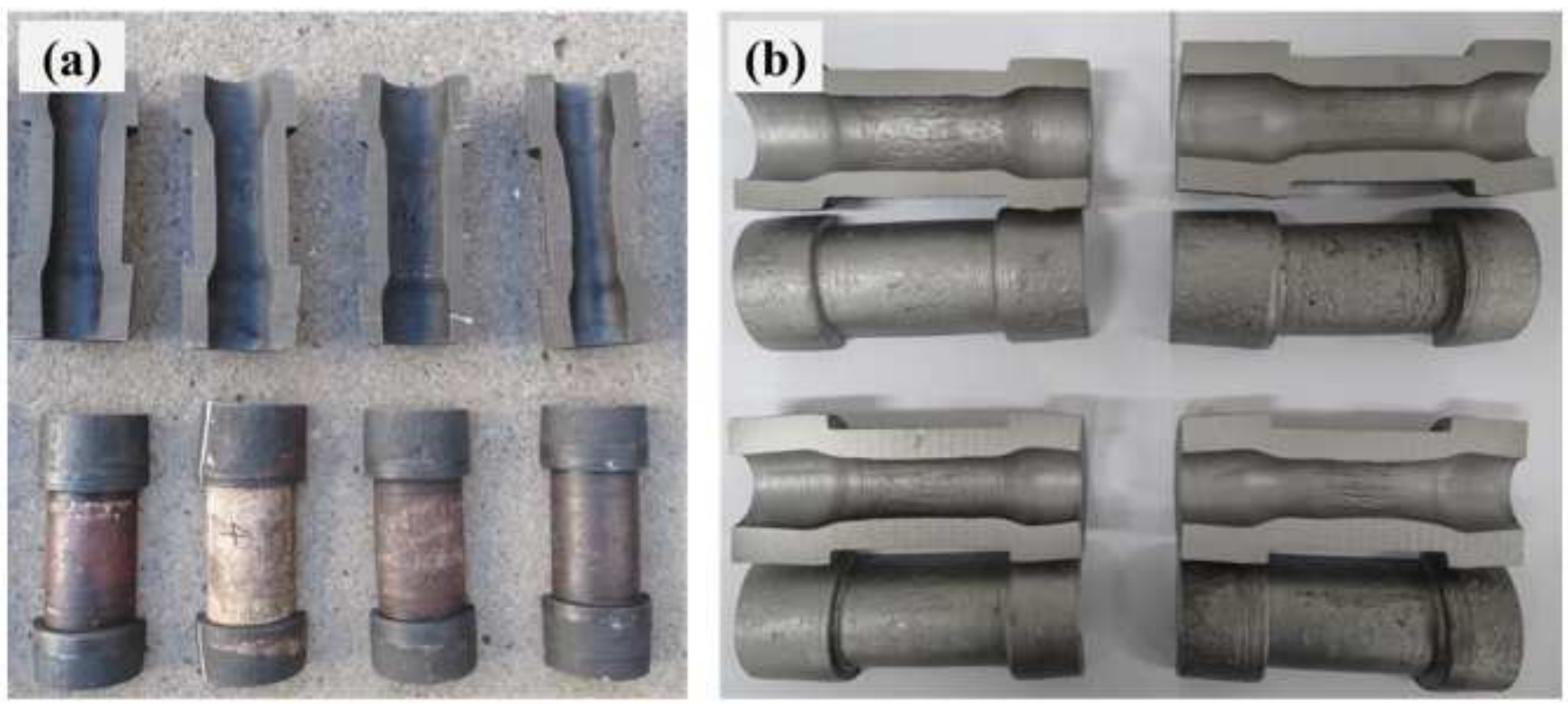
Figure 17

The FCWR produced hollow shafts: (a) initial status; (b) after shot peening

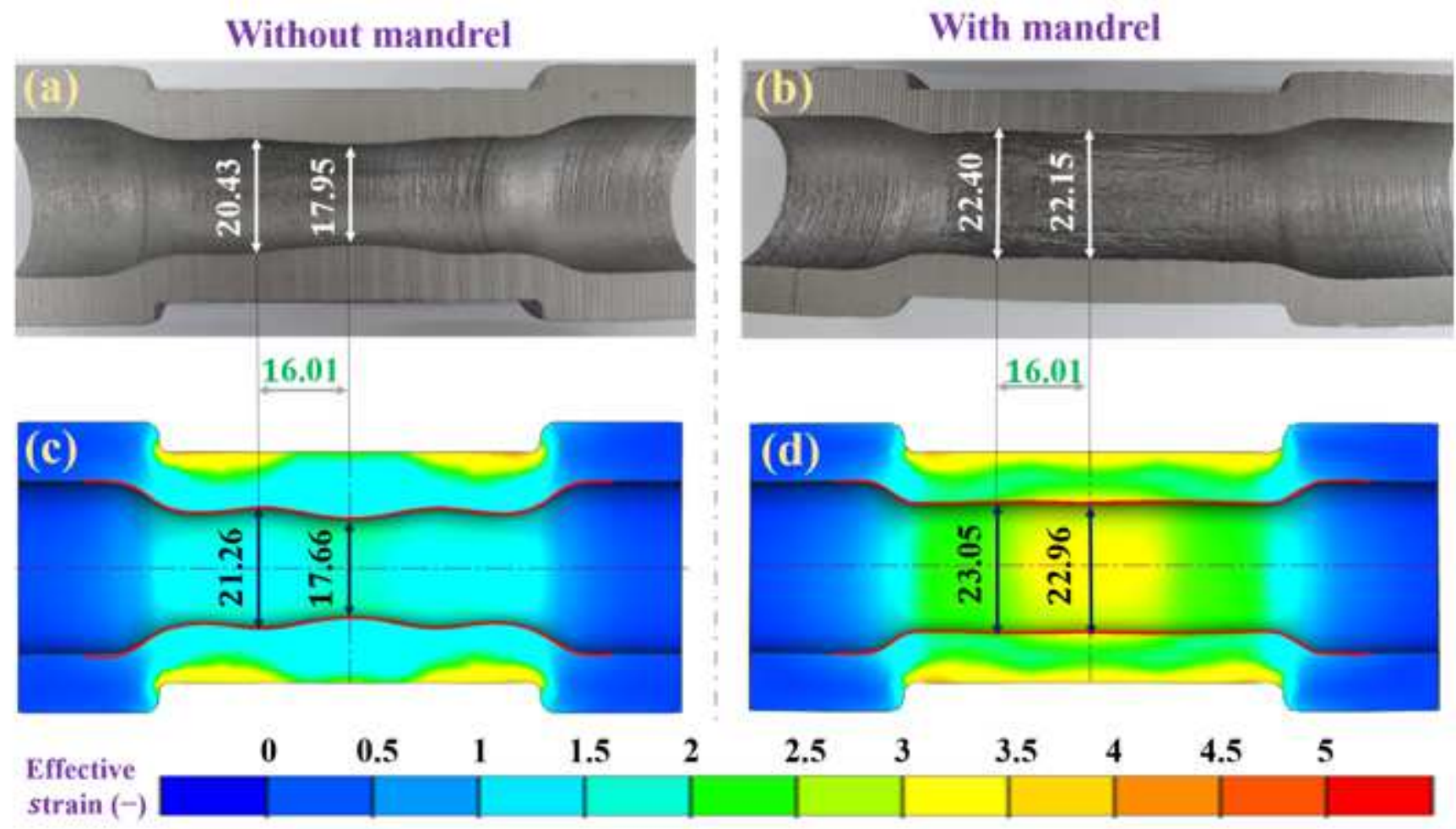

\section{Figure 18}

Geometry comparison between $(a, b)$ physical experiments and $(c, d)$ numerical simulations 


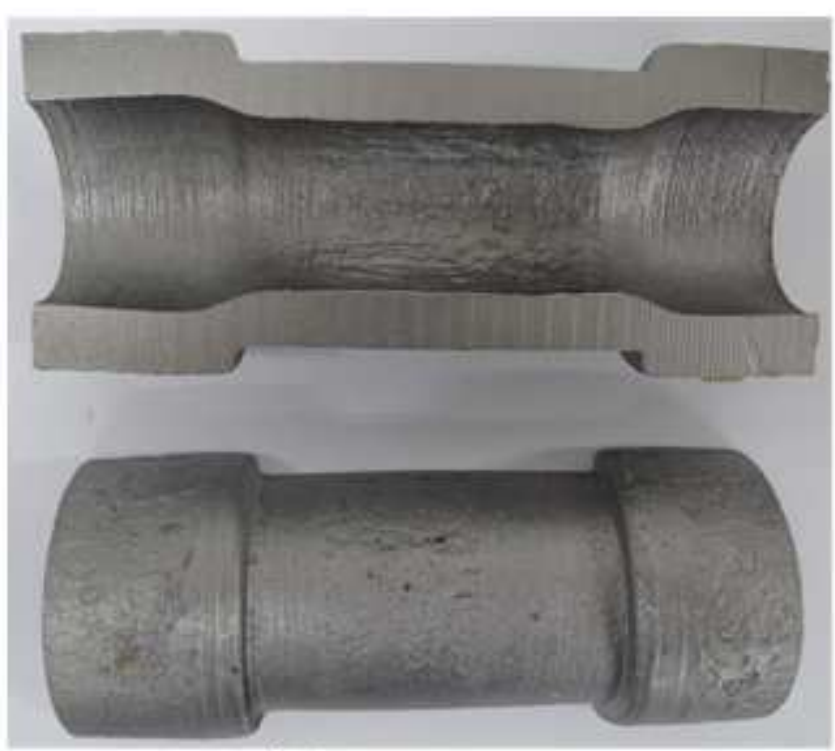

(a) $d_{0}=30 \mathrm{~mm}$

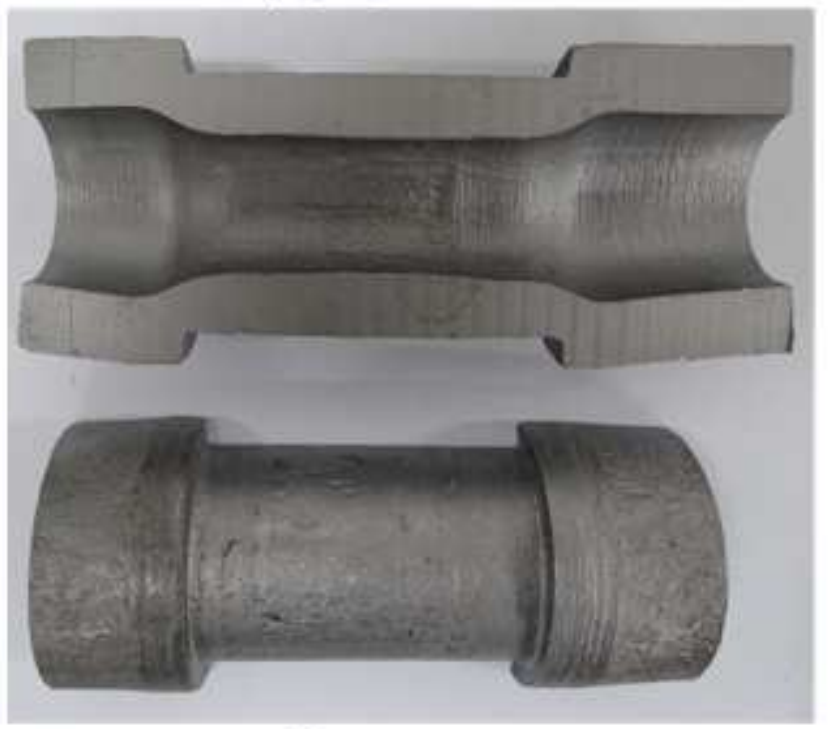

(c) $d_{0}=26 \mathrm{~mm}$

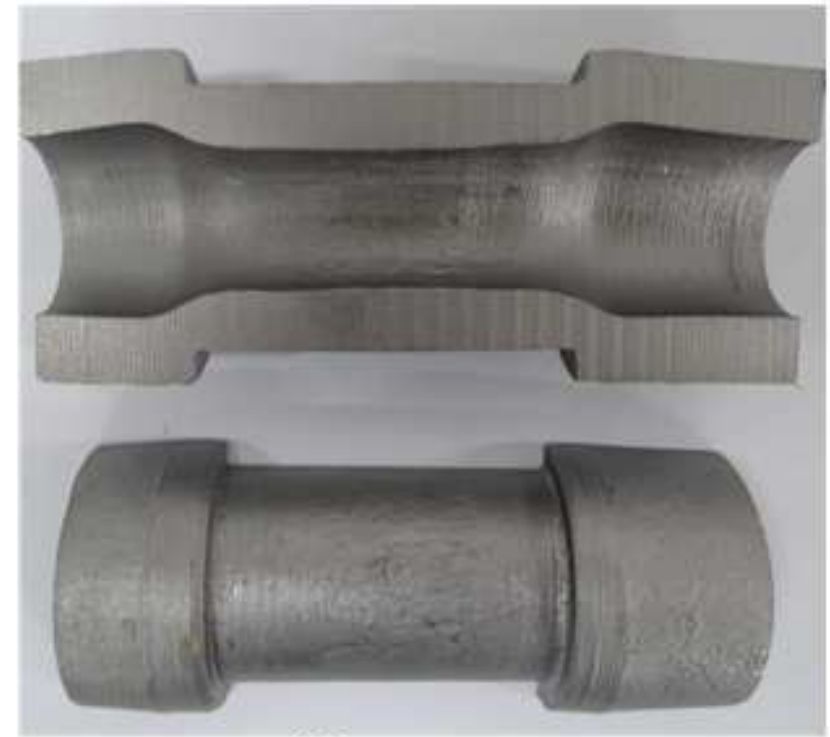

(b) $d_{0}=28 \mathrm{~mm}$

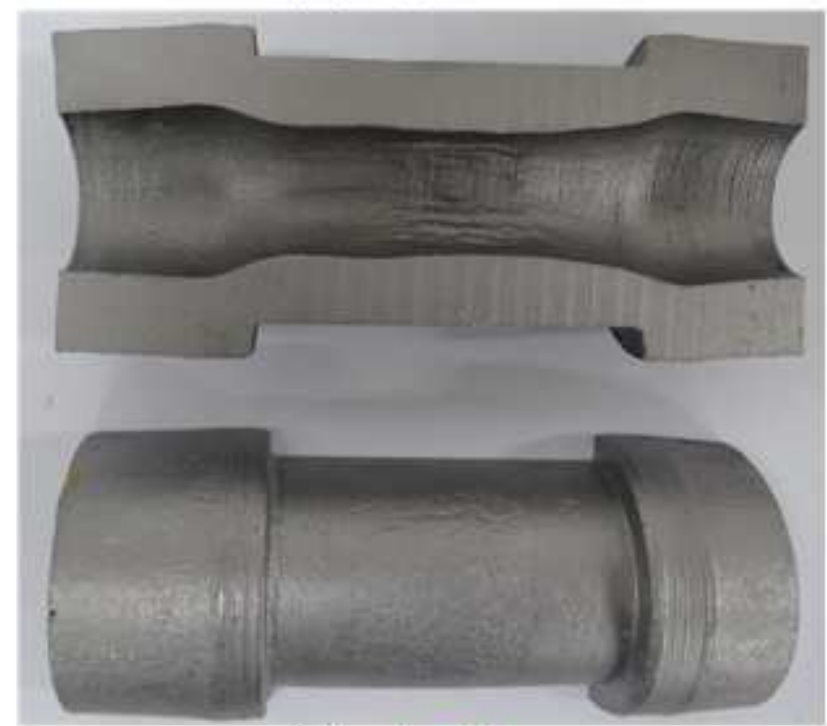

(d) $d_{0}=\mathbf{2 4 \mathrm { mm }}$

Figure 19

Hollow shafts formed by FCWR with single guide in the horizontal multifunctional mill 


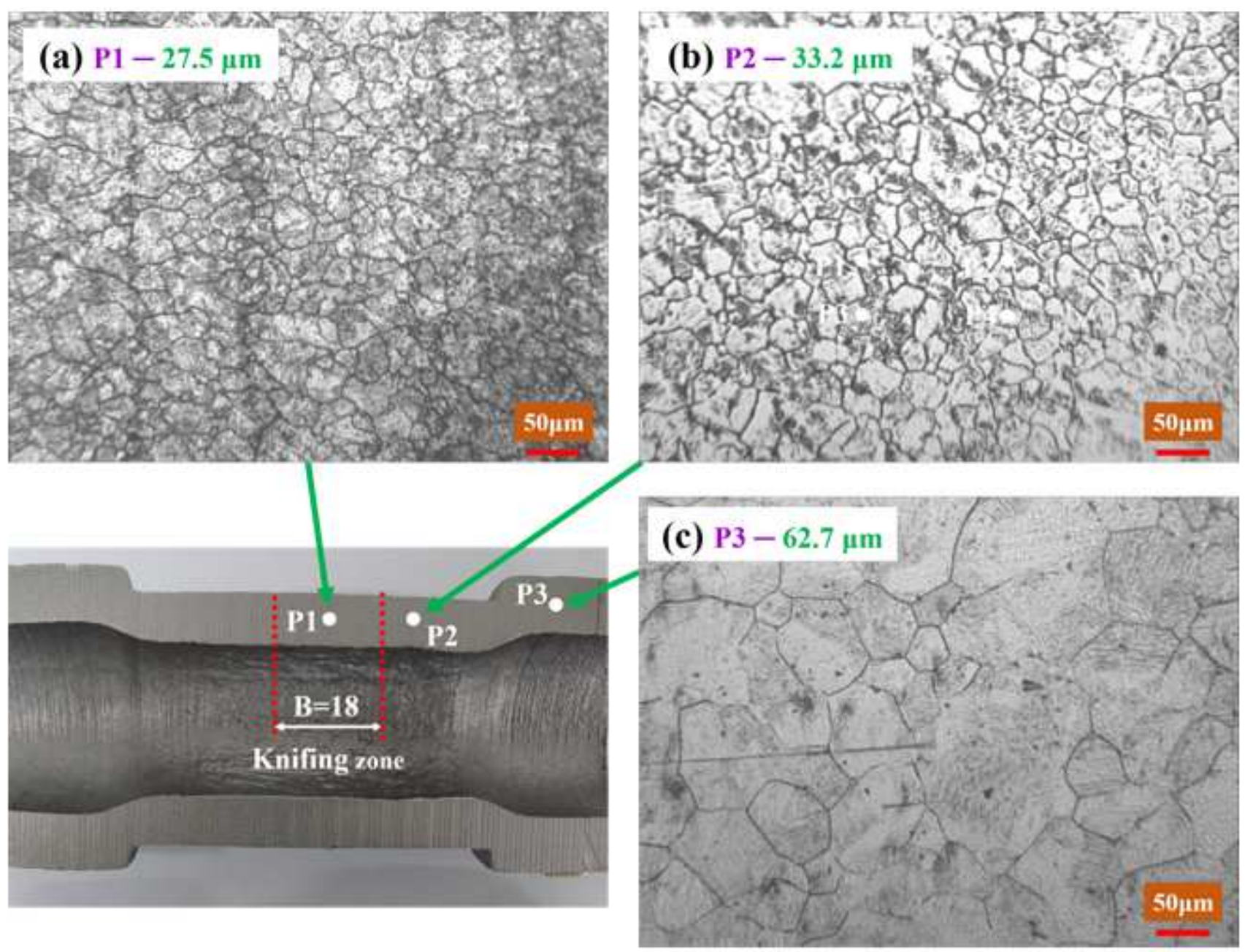

Figure 20

Grain size of the FCWR rolled shaft at different locations 